\title{
Interaction between hydraulic fractures and natural fractures: current status and prospective directions
}

\author{
Oladoyin Kolawole ${ }^{1}\left[\right.$ Ion Ispas ${ }^{2}$
}

Received: 25 July 2019 / Accepted: 19 September 2019 / Published online: 25 September 2019

(c) The Author(s) 2019

\begin{abstract}
Hydraulic fracturing treatment is one of the most efficient conventional matrix stimulation techniques currently utilized in the petroleum industry. However, due to the spatiotemporal complex nature of fracture propagation in a naturally- and often times systematically fractured media, the influence of natural fractures (NF) and in situ stresses on hydraulic fracture (HF) initiation and propagation within a reservoir during the hydrofracturing process remains an important issue. Over the past 50 years of advances in the understanding of HF-NF interactions, no comprehensive revision of the state of the knowledge exists. Here, we reviewed over 140 scientific articles on investigations of HF-NF interactions, published over the past 50 years. We highlight the most commonly observed HF-NF interactions and their implications for unconventional oil and gas production. Using observational and quantitative analyses, we find that numerical modeling and simulation is the most prominent method of approach, whereas there are less publications on the experimental approach, and analytical method is the least utilized approach. Further, we suggest how HF-NF interactions can be monitored in real time on the field during a pre-frac test. Lastly, based on the results of our literature review, we recommend promising areas of investigation that may provide more profound insights into HF-NF interactions in such a way that can be directly applied to the optimization of fracture-stimulation field operations.
\end{abstract}

Keywords Hydraulic fracture $\cdot$ Natural fracture $\cdot$ Interaction $\cdot$ Fracture network $\cdot$ Fracture propagation

\section{List of symbols}

$\theta$

List of symbols
$K_{\mathrm{I}}$
$K_{\mathrm{II}}$
$K_{\mathrm{IC}}$
$\Delta \sigma$
$\tau$

Approach angle $\left({ }^{\circ}\right)$

Stress intensity factor of mode-1

fracture

Stress intensity factor of mode-2

fracture

Fracture toughness of in situ rock

Differential horizontal stress (MPa)

Shear stress acting on the natural fracture (MPa)

Electronic supplementary material The online version of this article (https://doi.org/10.1007/s13202-019-00778-3) contains supplementary material, which is available to authorized users.

Oladoyin Kolawole

doyin.kolawole@ttu.edu

1 Bob L. Herd Department of Petroleum Engineering, Texas Tech University, 233 TFPER Bldg, Lubbock, TX 79409, USA

2 Bob L. Herd Department of Petroleum Engineering, Texas Tech University, 226 TFPER Bldg, Lubbock, TX 79409, USA $\tau_{0}$

C

$\sigma_{\mathrm{n}}$

$K_{\mathrm{f}}$

$\sigma_{\mathrm{H}}$

$\sigma_{\mathrm{V}}$

$T_{0}$

$P_{\mathrm{f}}$

$P_{\text {net }(i)}$

$K_{\mathrm{I}(i)}$

$n$

$l_{(i)}$

$l$

$P_{\sigma}$

$\sigma_{\theta}$
Inherent shear stress acting on the natural fracture $(\mathrm{MPa})$

Cohesion

Normal stress acting across the natural fracture plane $(\mathrm{MPa})$

Coefficient of friction (unitless)

Horizontal stress (MPa)

Vertical stress (MPa)

Tensile strength of the formation rock (MPa)

Fracture pressure (MPa)

Net pressure at different nodes (MPa) Integrated stress intensity factor of mode-I fracture

Number of pressure nodes along the changing fracture length Distance between initial point and the $i$ th pressure node $(\mathrm{m})$

Opened fracture length $(\mathrm{m})$ Treatment overpressure (MPa) Normal stress acting at a given approaching angle ( $\mathrm{MPa})$ 


$\begin{array}{ll}p & \begin{array}{l}\text { Pressure at the HF-NF intersection } \\ (\mathrm{MPa})\end{array} \\ \left(\sigma_{\mathrm{n}}-p\right) & \begin{array}{l}\text { Effective normal stress acting on the } \\ \text { natural fracture plane (MPa) }\end{array} \\ K_{\mathrm{I}}-\text { fluid pressure } & \begin{array}{l}\text { Stress intensity factor due to highly } \\ \text { pressured region by propagating } \\ \text { hydraulic fracture }\end{array} \\ & \begin{array}{l}\text { Critical fracture toughness due to } \\ \text { fluid lag region }\end{array} \\ K_{\mathrm{IC}-\text { lag }} & \begin{array}{l}\text { Fluid lag distance (m) } \\ \text { Fracture half-length (m) }\end{array} \\ L & \text { Fluid lag length (m) } \\ L_{\mathrm{f}} & \text { Hydraulic fracture radius (m) } \\ R & \text { Excess pressure in the wellbore } \\ P_{\mathrm{w}} & \text { (MPa) } \\ \sigma_{\text {tip }} & \text { Effective stress acting to close the } \\ \text { tip of propagating hydraulic fracture } & \text { (MPa) }\end{array}$

\section{SI metric conversion factors}

$\mathrm{m} \times 3.28084 \quad \mathrm{E}+00=\mathrm{ft}$

$\mathrm{MPa} \times 1.45 \quad \mathrm{E}+02=\mathrm{psi}$

\section{Introduction}

Hydraulic fracturing (hydrofracturing) is the process of injecting highly pressurized fluid into the formation to initiate fractures in order to stimulate production from formations with low permeabilities. Hydraulic fracturing is one of the most effective conventional reservoir-stimulation techniques that has been utilized over the past seven decades in the oil and gas industry. Hydraulic fracturing operations have been extensively investigated and widely published (Clark 1949; McLennan and Picardy 1985; King 2012, 2014; Zoback et al. 2012; Soliman et al. 2014; Sebastian et al. 2015; Yan and Zheng 2017; Feng and Gray 2018; Elwaziry and Soliman 2018; Elwegaa and Emadi 2018; Gale et al. 2018; Maity et al. 2018; Parsegov et al. 2018; Wigwe et al. 2018; French et al. 2019; Kolawole et al. 2019; Kumar and Ghassemi 2019a; Maity and Ciezobka 2019a, b; Wan et al. 2019; Wigwe et al. 2019a, b). The USA has been named as the largest global crude oil producer according to US Department of Energy report (EIA 2018); the tight shale gas and tight oil formations in the Permian and Bakken regions are two (2) among the top three (3) formations that have contributed to this feat. The existence of pre-existing natural fractures (NF) plays an important role in the economical characterization of prospective formations (Walton and McLennan 2013). Interactions between hydraulic fractures (HF) and natural fractures (NF) in unconventional reservoir, geothermal systems, and mining are a complex process which has not been fully understood. In unconventional reservoirs, geothermal wells (Toth et al.
2018, 2019; Kumar and Ghassemi 2019b), and cave mining (Sun et al. 2019), hydrofracturing process has proved to be efficient (Gil et al. 2011) in: improving the stimulated reservoir volume (SRV), providing faster and high-conductivity pathway into the reservoir, and overcoming near-wellbore damage (Moronkeji et al. 2015; William et al. 2019) and sand production (Kolawole et al. 2018a) into the wellbore during drilling and completions operations (Willson and Armagost 2004). The underground complex fracture-induced system of NF-HF behavior is highly important to be meticulously and efficiently characterized during hydrofracturing process (Xiao et al. 2017).

Based on classical fracture mechanics, three (3) modes of rock failure have been widely recognized. The tensile or extensional fracture (mode- 1 fracture) is a brittle discontinuity in which the opening direction is perpendicular to the fracture plane without any shear (slip) along the plane. Mode-2 failure is characterized by lateral shear (slip) along the natural fracture, and it is known as shear fracture. Lastly, mode-3 fracture is a vertical tearing fracture with a vertical shear along the NF plane without any appreciable stretching or shortening of the NF plane. Normal or reverse faults dominate this rock failure. These fracture modes describe the mechanical failure of geological brittle discontinuities at multiple scales, for example, micro-, meso- to macro-laboratory and field scales (e.g., this study; Einstein and Dershowitz 1990; Rutledge and Phillips 2003; Maxwell et al. 2009) and mega- field scales (e.g., Ayalew et al. 2004; Kolawole et al. 2018b). They are also found to characterize brittle deformation in geological materials of varying mechanical strengths such as unconsolidated sediments (e.g., Kolawole et al. 2017, 2018b), sedimentary rocks (e.g., Milad and Slatt 2018; Milad et al. 2018), and hard rocks (e.g., Segall and Pollard 1983; Katz and Reches 2004; Bertrand et al. 2015; Kolawole et al. 2018c). However, this paper only considers the micro-, meso- to macroscale fracturing of reservoir rocks, and the classic fracture modes (mode-1 to 3 ) encompass the range of mechanical behavior that characterize $\mathrm{HF}-\mathrm{NF}$ interactions discussed in this paper.

Over the past 50 years of advances in the understanding of $\mathrm{HF}-\mathrm{NF}$ interactions, prior to this contribution, there exists no comprehensive review of the state of knowledge. Previous review on HF-NF interaction (Taleghani et al. 2016) only focused on numero-mechanical models for $\mathrm{HF}-\mathrm{NF}$ interactions. A portion of our preliminary overview included in this paper has been presented in Kolawole and Ispas (2019a). In this paper, we discussed and summarized the key findings regarding interactions between hydraulic fracture and natural fractures since the 1960s up until 2018. The governing equations, as well as widely documented and newly observed interaction behavior are reviewed. We also reviewed influential mechanical parameters, methods of approach in HF-NF interaction studies, and the fracture networks created. We extensively compared and outlined the 
spatiotemporal practicality, modifications, and drawbacks of published research studies. Finally, we proposed how the mechanics of HF-NF interactions can be monitored in real time on the field during a pre-frac test. We provided recommendations for future research to address the identified outstanding and persistent problems related to interactions between hydraulic fractures and pre-existing natural fracture.

\section{Governing equations}

The two (2) most-adopted 2D HF propagation models are: Khristianovic-Geertsma-de Klerk (KGD) model (Khristianovich and Zheltov 1955; Geertsma and de Klerk 1969) and Perkins-Kern-Nordgren (PKN) model (Perkins and Kern 1961; Nordgren 1972). Hydraulic fracture propagation and pressure response are highly influenced by the presence of natural fractures. The change of confining stresses at the discontinuity and the displacement effect of a propagating HF influences complex HF-NF interaction mechanics. Assuming a homogenous, isotropic, and elastic reservoir in Shrivastava et al. (2018), the stress region around a pre-existing NF (Zangeneh et al. 2015) undergoes compression (shadowed by the growing $\mathrm{HF}$ ) and tension (NF region in front of HF) as the HF nears the NF. There is possibility of partial failure in the alternating tensile and compressive stresses region. The approach angle $(\theta)$ is the angle between maximum horizontal stress direction and the pre-existing natural fracture.

The criteria for HF propagation were given by Erdogan and $\mathrm{Sih}(1963)$ as:

$\cos \frac{\theta}{2}\left[K_{\mathrm{I}} \sin \theta+K_{\mathrm{II}}(3 \cos \theta-1)\right]=K_{\mathrm{IC}}$

The differential horizontal stress acting on the plane of the natural fracture can be estimated using Cheng et al. (2014a, b):

$\Delta \sigma=K_{\mathrm{f}} * \sigma_{\mathrm{n}}+C-\tau$

The crossing criterion in Renshaw and Pollard (1995) has been widely adopted in several studies to validate the numerical simulation crossing results. This (Eq. 3) is only based on a $2 \mathrm{D}$ vertical-horizontal plane. In developing the crossing criterion, compressive stress was assumed to be positive.

$\frac{\sigma_{\mathrm{H}}}{T_{\mathrm{o}}+\sigma_{\mathrm{v}}}>\frac{0.35+\frac{0.35}{K_{\mathrm{f}}}}{1.06}$

The left-hand side of Eq. (3) is defined as the critical crossing stress ratio. The crossing criterion can also be expressed by considering fracture propagation in horizontal plane, and the approach angle $(\theta)$, and assuming the opening pressure will exceed the fracture re-initiation pressure to give (Blanton 1986):
$\frac{\sigma_{\mathrm{H} \max }-\sigma_{\mathrm{H} \min }}{T_{o}}>-\frac{1}{\cos 2 \theta-b \sin 2 \theta}$

If the left-hand side of Eqs. (3) and (4) is greater than the right-hand side or if the crossing stress ratio in Eq. (3) exceeds 0.99 , the HF is assumed to cross the pre-existing NF. Likewise, if the right-hand side of Eqs. (3) and (4) is greater than the left-hand side or if the crossing stress ratio in Eq. (3) is below 0.99, the HF will be expected to "terminate" or get arrested at the pre-existing NF. Therefore, the conditions stated in Eqs. (3) and (4) satisfy the expected crossing behavior in HF-NF interactions.

The criteria for NF dilation were given by Song et al. (2014) as:

$P_{\mathrm{net}(i)}=P_{\mathrm{f}(i)}-\sigma_{\mathrm{n}}$

$\sum_{i=1}^{n} K_{\mathrm{I}(i)}\left(P_{\mathrm{net}(i)}, l_{(i)}, l\right) \geq K_{\mathrm{IC}}$

Equations (5) and (6) were modified by Chen et al. (2014) to give:

$p_{\sigma}>\frac{\left(\sigma_{\mathrm{H}_{\max }}-\sigma_{\mathrm{H}_{\min }}\right)(1-\cos 2 \theta)}{2}$

The criteria for NF shearing were given by Cheng et al. (2014a) and Chen et al. (2014) as:

$\left|\tau_{\mathrm{o}}\right|<\tau_{\mathrm{o}}-K_{\mathrm{f}} * \sigma_{\theta}$

Equation (9) provides the condition where shear will not occur in the natural fracture.

$\left|\tau_{\mathrm{o}}\right|>\tau_{\mathrm{o}}-K_{\mathrm{f}} * \sigma_{\theta}$

$|\tau|>\tau_{\mathrm{o}}+K_{\mathrm{f}}\left(\sigma_{\mathrm{n}}-p\right)$

\section{HF-NF interactions}

Hydraulic fracture propagates (Fig. 1a) parallel to the maximum horizontal stress $\left(\sigma_{\mathrm{H} \max }\right)$ and perpendicular to the minimum horizontal stress $\left(\sigma_{\mathrm{Hmin}}\right)$. As the propagating $\mathrm{HF}$ intersects with pre-existing NF, some possible interaction behavior scenarios can be expected. The complex behavior created by HF-NF interaction was by virtue of merging and/or branching of the HFs upon intersecting with NFs in unconventional reservoirs.

\section{Arrest of HF}

Arrest of the HF (Fig. 1b) without further growth (also known as termination) is discussed in this section. When a propagating HF does not cross a pre-existing NF and it terminates at the NF interface, we have a HF arrest behavior 

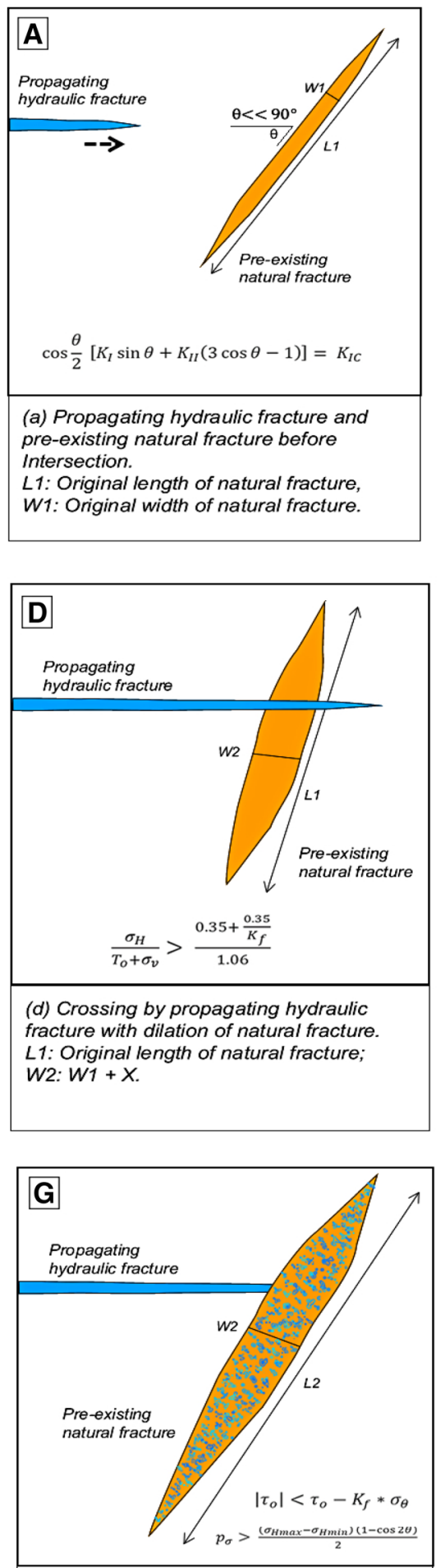

(g) Reactivation of pre-existing natural fracture by shearing and dilation.

$L 2: L 1+X$;

$W 2: W 1+X$

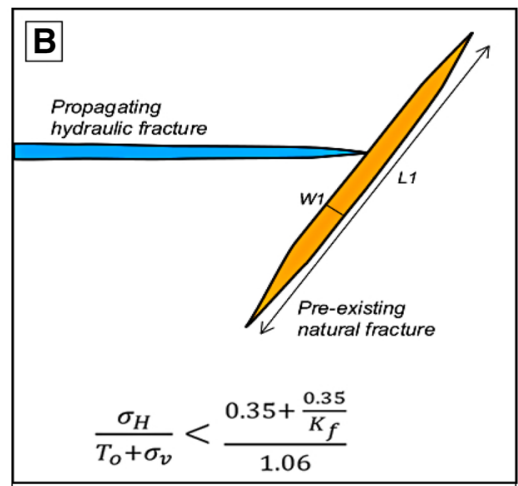

(b) Arrest interaction behavior between propagating hydraulic fracture and pre-existing natural fracture after intersection.

L1: Original length of natural fracture, W1: Original width of natural fracture.
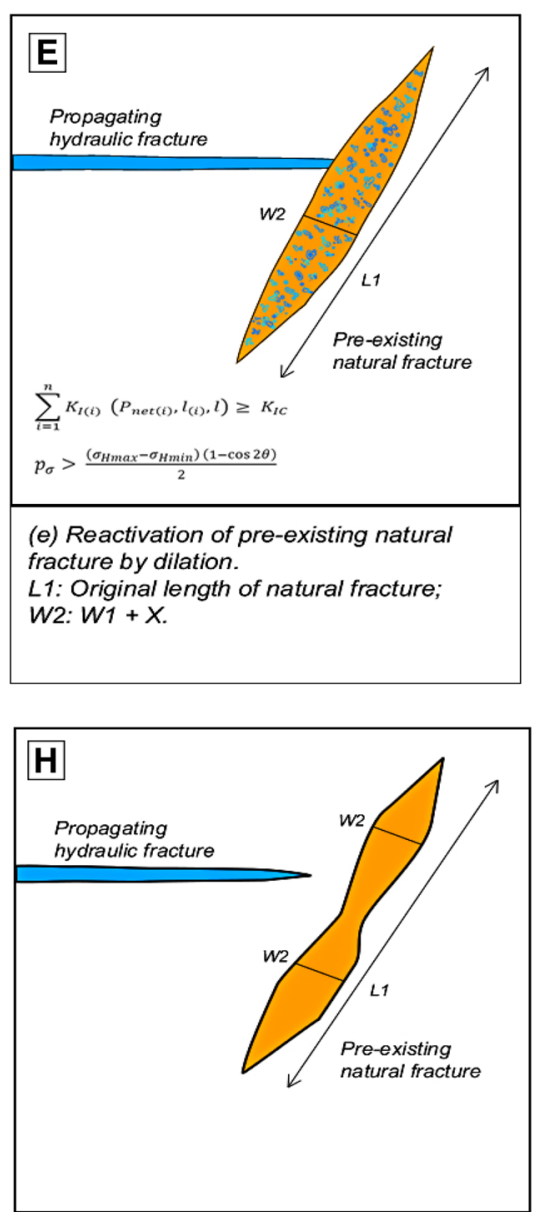

(h) Debonding of the natural fracture prior to intersection with propagating hydraulic fracture.

$L 1$ : Original length of natural fracture; $W 2: W 1+X$

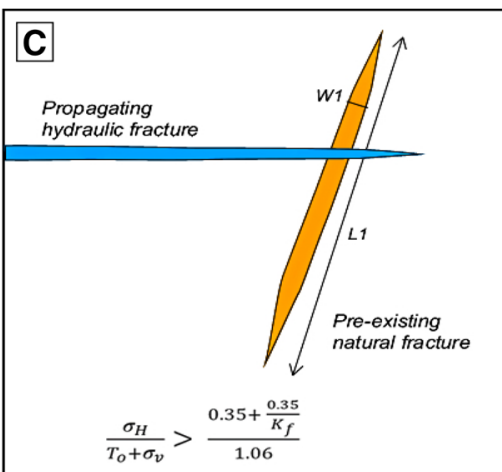

(c) Crossing by propagating hydraulic fracture without dilation of natural fracture L1: Original length of natural fracture, W1: Original width of natural fracture.

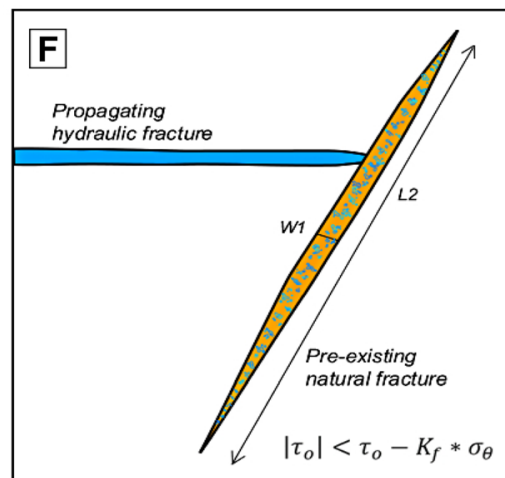

(f) Reactivation of pre-existing natural fracture by shearing.

L2: $L 1+X$;

$W 1$ : Original width of natural fracture

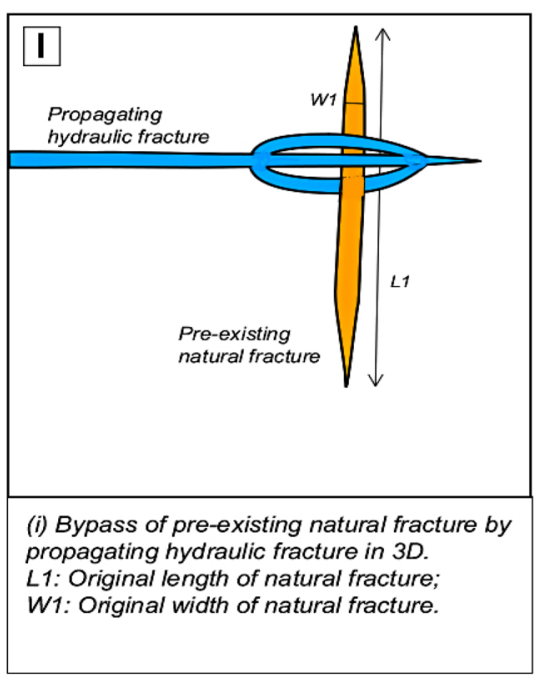

Fig. 1 Widely documented and newly observed interaction behavior between propagating hydraulic fracture and pre-existing natural fracture 
(Gu and Weng 2010). Notwithstanding the high approach angle of $90^{\circ}$, a poorly cemented NF interface will arrest a propagating NF, and/or slip under shear. For fully cemented NF interface (Fu et al. 2015a), the HF will be arrested during intersection with a pre-existing fracture and no crossing was observed, concluding that the NF interface with less un-bonding will always arrest a propagating HF. The Damjanac et al. (2010) test well results from lower Silurian Longmaxi shaly formation of Sichuan basin validated the arrest of the propagating HF at the NF interface. At low $\left(20^{\circ}\right)$ approach angle, the right side of a propagating dual-winged HF was arrested at NF interface, while the left side of the HF will deflect fluid into the proximate NF after intersection. When the angles between the NF plane and the maximum horizontal stress direction decrease, the HF will get arrested at the NF plane (Wang et al. 2018a; Fatahi et al. 2017). Olson et al. (2012) concluded from a hydrostone block experiment results that oblique $\mathrm{HF}-\mathrm{NF}$ intersections will lead to arrest or diversion of the propagating HF along the NF interface at sub-orthogonal.

Meanwhile, at low fluid viscosity and pump displacement, propagating HFs will be arrested by the NF. In the results presented by Cheng et al. (2014b), the HF was arrested at the pre-existing fracture due to horizontal stress difference $(\Delta \sigma)$ falling below an estimated critical value of horizontal stress difference. At low-to-intermediate approach angles and high differential horizontal stresses, the HF will get arrested and terminate at the NF upon intersection (Zhu et al. 2018).

Decrease in the differential horizontal stresses at this low approach angles will likely alternate the fracture network created after HF-NF intersection. When HFs with two (2) different fluid viscosities (low and high viscosities) intersecting multiple NFs were investigated by Seok Yoon et al. (2017), the HF propagated by the low viscosity fluids was observed to get arrested at the NF. The high viscous fluids caused the propagating HF to induce a higher local stress around the NF-HF intersection, thereby creating a more complex network of fractures. GEOS was also adopted by Morris et al. (2016) and Huang et al. (2018) to investigate the effects of natural fracture and closure stress interactions with a propagating HF. The 3D simulation results show the HF will be arrested at the NF interface and fail to cross the stress barriers. The HF arrest is due to height constraint of the NF within the stress barriers, which will impede the HF from crossing the stress barriers. Arrest of HF was observed in Yildirim et al. (2018a) when the stiffness ratio $(\mathrm{kn} / \mathrm{ks})$ is lower than intact rock matrix, while higher stiffness ratio resulted in direct crossing.

\section{HF crossing the NF}

To optimize production, the hydraulic fracture crosses the NF (Fig. 1c) and connects with other pre-existing NFs without increasing the width of the NF (dilation). The HF will be expected to cross the NF: (1) when the maximum tensile stress at HF tip is equal to the tensile strength of rock on opposite side of the NF; (2) No shear slip (Eqs. 10, 11) of the NF; (3) when the horizontal stress difference exceeds an identified critical horizontal stress value.

NF commonly contains mineral fills in which case the bonding strength along the fracture interface is determined by the mechanical strength of the mineral fill. Common mineral fills are quartz, calcite, epidote, and pyrite. Ductile intervals in shale have low Young's modulus and high Poisson's ratio, while moderate-to-high Young's modulus and low Poisson's ratio are influential characteristics of brittle intervals in shale formations (Grieser and Bray 2007). In strongly bonded NF interface (high Young's modulus and low Poisson ratio), the propagating HF was observed by Wang et al. (2018b) to cross the NF interface. The results showed that high approach angle and high fracture energy, and optimum cement thickness are essential for the HF to cross the interface of the pre-existing NF. At near-orthogonal approach angle, the propagating HF cuts through the NF interface without any offset along the NF. An outstretched HF will be formed, which creates less-complicated fracture network. At moderate approach angle of $60^{\circ}$, the propagating HF was observed to cross the NF with certain offset along the NF (unidirectional stepping) (Fig. 13). Out of the four (4) tests conducted by Kear et al. (2017), two (2) show crossing of the HF at orthogonal NF-HF interface angle $\left(90^{\circ}\right)$ and crossing stress ratio of 1.4 , while the other two (2) test results did not show crossing. The results of the numerical simulation appeared to match the crossing behavior in the experimental results. The authors concluded that the disparities in treatment pressure and HF growth rates between the numerical and experimental results may be due to either the frictional stresses between siltstone and vinyl faces, or because of inadequate understanding of the interface permeability.

In combining an experimental triaxial test with quasistatic and adaptive meshing scheme, Meng and de Pater (2010) observed that at a high normal confining stress and strong NF interface bonding, the propagating HF tends to cross the NF interface. Fluid injection properties, confining stress, fracture initiation point, and NF coupling could also be observed to influence HF-NF interactions. A pre-sheared NF will likely not allow crossing by the propagating HF. In the results of Aimene et al. (2018), a propagating HF will tend to get terminated at weakly bonded NF interface with an anomaly far from injection port. The HF may cross strongly bonded interfaces but will only cross weakly bonded NF interface with an anomaly close to the injection port. In two-dimensional Huang et al. (2014) study, propagating HF will always directly cross a strongly cement-bonded NF at orthogonal angle. Taleghani and Olson (2013) showed that

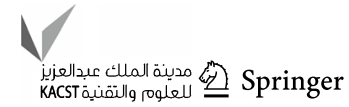


as the cement-fracture toughness threshold value exceeds that of the rock matrix by $25 \%\left(G_{\text {frac }} / G_{\text {rock }}>0.25\right)$, the HF will cross the NF at orthogonal angle. In using MPM method, continuous fracture models and Eagle Ford microseismic data, Umholtz and Ouenes (2015) investigated the optimum fracture initiation location that a propagating HF will likely cross a fault block (NF) after intersection at orthogonal approach angle. The HF-NF crossing interaction behavior in combination with higher stress anisotropy will produce a less complex fracture network.

Chen et al. (2014) observed that at low approach angles, crossing will not likely occur, but have higher possibility at high approach angle. Increase in differential horizontal stress favors the propagating $\mathrm{HF}$ to cross the interface pre-existing NF by impeding NF interface slip, and this is conformity with the crossing the criterion. When the boundary of crossing exceeds the differential horizontal stress at approach angles greater than $45^{\circ}\left(>45^{\circ}\right)$, the HF will cross the NF after intersection (Zhao et al. 2016, 2019a). In Fatahi et al. (2017), results from discrete element method (DEM) and true triaxial stress cell (TTSC) shows that the propagating HF will be more likely to cross the natural fracture as the angles between the NF plane and the maximum horizontal stress direction increases. At orthogonal angle in Cheng et al. (2014a), the two (2) HFs crossed the NF plane after intersection due to the elliptical HF tip and alternating lownormal and high-shear stresses by the two propagating HF tips. At high horizontal differential stress, and at greater or equal to $60^{\circ}$ approach angle, Keshavarzi and Jahanbakhshi (2013) observed crossing of the pre-existing NF by the propagating HF. The results from semi-circular bending test (Wang et al. 2013, 2018b) show that at high approach angle, the propagating HF tends to directly cross the preexisting NF without any influence from the NF width. Few results from Wang et al. (2013) also show that at orthogonal approach angle, the HF tends to cross the NF interface with a short offset on the NF interface after intersection. Wu and Olson (2014) showed the length of pre-existing NF influences $\mathrm{HF}-\mathrm{NF}$ fracture network created.

When HF intersects a short NF at a high approach angle, it crosses the NF interface and the length of the NF is increased after crossing. At high fluid viscosity and pump displacement, a propagating $\mathrm{HF}$ is liable to cross the NF (Cheng et al. 2014b). For intermediate fluid viscosity and displacement, a propagating HF has the tendency to sidestep the NF interface after crossing. At high injection rate, high differential horizontal stresses, high fluid viscosity, and high approach angles, the HF is inclined to cross the preexisting NF (Zhou and Xue 2011; Chen et al. 2015). The study by Zhu et al. (2018) shows that under high differential horizontal stresses and high approach angles, the propagating HF tends to always cross the pre-existing NFs if there is a decrease in the distance between injection point and the NF. In He et al. (2015) and Daneshy (2019), the propagating HF will only cross the NF when there is a very low NF tensile strength, and sufficiently high differential horizontal stress, high NF dip angle and high approach angle. At orthogonal angle, as described by Nikam et al. (2016), the approaching HF crossed the NF without dilating the NF interface. As the multiple propagating HFs cross the NFs, the energy of the HF reduces thereby weakening the prospect crossing subsequent NFs.

Direct crossing is expected to be observed when fracture friction angle nears the intact rock matrix value. A pre-existing NF with high interfacial shear capacity will be expected to experience crossing by an approaching $\mathrm{HF}$ after $\mathrm{HF}-\mathrm{NF}$ intersection. The HF will also likely cross a low interfacial shear capacity NF only after fluid pressure build-up. According to Zhou et al. (2015), low-permeable NF, high approach angle, high injection rate, and large NF interface cohesion coefficient tend to encourage direct crossing of the NF by the HF. In Wang et al. (2018a), if the in situ-rock cement friction coefficient exceeds 0.6 , the HF will likely cross the NF and will not get arrested nor divert upon intersection with the NF. Hou et al. (2015) further emphasized that brittleness is one of the most important parameters in hydrofracturing operations, since less complex fracture networks will be created in shales with higher brittleness. Due to alternating effects of gouge formation and fracture dilation, HF conductivity may remain constant under large effective stresses (Moradian et al. 2016).

$\mathrm{HF}$ crossing the NF and leading to increase in the width of the NF (Fig. 1d) is another widely observed HF-NF interaction behavior. By adopting a coupled discrete fracture network (DFN) and dual-lattice DEM (DL-DEM), Zhou et al. (2016) observed a new HF-NF interaction behavior. It was observed that competing effect between crossing-favorable approach angle and dilating-favorable viscosity will cause the propagating HF to dilate the NF while crossing the NF interface. Using a field-derived DFN explicit model, propagating dual-winged HFs was observed to cross a pre-existing NF at orthogonal angle (Damjanac et al. 2010) without any change in direction or dilation of the interface. Combination of dilation and crossing may observed occur due to intermediate approach angle $\left(60^{\circ}<\theta<90^{\circ}\right)$ and a high differential horizontal stress $(10 \mathrm{Mpa}<\Delta \sigma)$. The increase in the number pre-existing fractures will boost the likelihood of experiencing direct crossing and reactivation by dilation during HF-NF intersection (Yildirim et al. 2018a). In the Fu et al. (2015b) results, the approaching HF completely crosses the interface of a fully cemented NF with no offset, whereas in a partially cemented NF with large bonded area, HF crossing the NF was also observed. For partially cemented NF with extra-small bonded area, the HF dilated the NF while crossing the NF interface. A finite element model (FEM) was developed and incorporated with fluid mechanics in 
the hydrofracturing process to study the NF-HF interaction (Celleri et al. 2018; Serebrinsky et al. 2017). The results show opening of the NF (dilation) behavior which transitioned into crossing with increase in injected fluid viscosity. When the in situ-rock fracture toughness (Oyedokun and Schubert 2017) falls below the normal stress on a NF, the propagating HF will cross the NF plane. Nonetheless, when the natural fracture toughness exceeds the treatment pressure at intersection point, the propagating HF will temporarily terminate at the NF, before dilating the NF and begin to cross the NF (Potluri et al. 2005). The Gu et al. (2011) triaxial test result validates the crossing criterion (Renshaw and Pollard 1995) and showed that at orthogonal approach angle $\left(90^{\circ}\right)$, the HF crosses the NF. Meanwhile, at $60^{\circ}$ approach angle, the HF dilates the NF as it crosses the NF after intersection. The Guo et al. (2015) numerical and experimental results also validated the NF dilation after HF crossing at high approach angles.

\section{NF reactivation}

We herein define NF reactivation as mode-1 (dilation), mode- 2 or mode- 3 (shear) activation of a pre-existing natural fracture due to stress interaction with an approaching HF. NF reactivation may or may not lead to lengthening (tip propagation) of the NF. If the HF does not propagate across a pre-existing NF, and instead reactivates the NF plane as mode-1 activation, we have a dilation behavior (Fig. 1e). Germanovich et al. (2012) considered the confining stress to be most important in optimum injection pressure determination, and the HF growth can only be expected in the toughness-dominated region in unconsolidated materials. In $\mathrm{Gu}$ et al. (2011) triaxial tests, HF propagating at a low approach angle $\left(30^{\circ}\right)$ to the NF will likely get arrested at the NF interface, and/or fuse into the NF and activates tip of NF by dilation. Dilation of pre-existing NF can result in increased HF fluid loss and operational failure (Pankaj and Li 2018), but highly permeable regions of the pre-existing NFs will likely arrest the HF fluids at the NF interface. In addition to NF temporarily arresting a propagating HF, Wang et al. (2018b) also observed that HF can divert into the NF and causes the interface to dilate. The interface of the NF was observed to dilate after intersecting with a HF due to the high fluid rate and fluid viscosity of the $\mathrm{HF}$ ( $\mathrm{He}$ et al. 2015). At low approach angle, the fracture overpressure force $P_{\sigma}$ acts at the HF tip making the NF interface to "open-up" and increase in width, propagating the tip of the NF and thus dilating the NF (Chen et al. 2014). The authors concluded that high differential horizontal stress and low approach angle will permit dilation of the NF interface. The effects of in situ stress, strength of NF, and the approaching angle on HF-NF interactions were investigated by Guo et al. (2015). The cohesive zone finite element result was validated with the experimental triaxial test result using laminated block. The crack opening displacement (COD) also known as hydraulic fracture width was used by Moradi et al. (2017) to investigate the behavior of HF upon intersecting a pre-existing NF. Lower NF spacing will tend to divert the propagating NF into the NF, and the NF tip will continue to propagate by dilation of the NF interface. Due to highly permeable NF, low viscous HF, and lower injection rates, Zhou et al. (2015) observed the NF dilating upon intersection with the propagating HF after initially arresting the HF. The propagating HF will be expected to dilate instantly when the injection pressure is higher the normal stress acting on the NF (Potluri et al. 2005; Xie et al. 2018). As the propagating HF changes the local stress field when induced, the fluid continues to discharge into the NF, until the NF tip begins to dilate and propagate out of the NF to connect with the next pre-existing NF (Mack 2016). Although the dominant interaction behavior is the reactivation of pre-existing NFs by shearing, but the results of DFN modeling and microseismic analysis of calcite-filled core by Williams-Stroud et al. (2012a) showed dilation of NF because of tensile failure. The results from Dershowitz et al. (2010) showed shear reactivation and extension of the NF upon intersection with a HF. The DFN approach (Suboyin et al. 2018) is consistent with the observed microseismic behavior (Williams-Stroud et al. 2012a), and an improved well production and fracture behavior forecast can be provided.

Some NF tips are likely to propagate by shearing (mode2 ). When a propagating HF does not propagate across a pre-existing NF, and instead propagates the tip of the NF resulting in shear of the NF interface, we have a shearing behavior (Fig. 1f). Crossing is less likely to be observed at low stress ratios, and smaller NF-HF angle of intersection (acute approach angle), which would result in slip of the interface (shearing) (Gu and Weng 2010). In weakly bonded rock-NF interface with shallow burial depth, low approach angle, and NF of high cement thickness, propagating HF will get arrested at the NF interface, and later resulting in NF slip which tends to deflect the HF after intersection (Zhou et al. 2015). At low approach angle $\left(30^{\circ}\right)$ and low fracture toughness (0.32 MPA), the propagating HF will likely "halt" at the NF interface and divert into the NF (Keshavarzi and Jahanbakhshi 2013; Taheri-Shakib et al. 2016b). Yang et al. (2016) showed that horizontal propagating HFs tend to be arrested by NF due to strongly cemented matrix, and the HF is also likely to reactivate the NF tip by shearing. From the result, a secondary tensile fracture growth can be observed from the tip of reactivated sheared NF, thereby creating a twist-like fracture network. The propagating HF tends to divert into the pre-existing $\mathrm{NF}$ and slip after intersection regardless of the thickness and width of the NF according to Wang et al. (2013), as the samples tested are both strongly and weakly cemented. This was observed at low approach

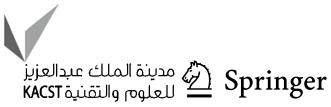


angles to increase the complexity of the fracture network created after intersection. At low differential horizontal stresses and low approach angles in Zhu et al. (2018), the HF will cause the NF plane to slip and reactivate the NF upon intersection. This will result in elongation of the NF due to shear and prevent the HF from crossing the NF if the distance between injection point and the NF extended.

In Taleghani and Olson (2011), the HF is observed to slide and shear rather than increase the width after intersection with a growing $\mathrm{HF}$ at approach angle of $60^{\circ}$. As discussed in Moradian et al. (2016), shearing of the NF plane will likely be induced due to high stress anisotropy, since the shearing of the NF is less than maximum asperity wavelength and opening of HF. In shales with higher than $30 \%$ clay, the slip on the faults is likely to occur slowly, which would enhance the hydrofracturing process in gas reservoirs with low permeability (Zoback et al. 2012). At approach angles less than $45^{\circ}$ in Zhao et al. (2016), the boundaries of $\mathrm{NF}$ tip and re-orientation exceeds the differential horizontal stress, the HF will not be able to cross the NF due to change orientation of HF propagate along the tip of NF. Finite element method (FEM) was used to model how natural fracture thickness affects HF-NF interaction (Wang et al. 2018a). The results show that for in situ-rock cement friction coefficient below 0.3 , the propagating HF will tend to divert along the NF plane. In studying the effect of shear failure on HF-NF interactions, Agrawal et al. (2019) observed the diversion of $\mathrm{HF}$ after intersecting a pre-existing NF will be more pronounced in highly permeable rock than what has been observed over the years in lowly permeable rocks. Wang et al. (2018b) observed that the induced arrest of the propagating $\mathrm{HF}$ is sometimes accompanied by shearing stress. Mighani et al. (2018a) observed that in poly (methyl) meta acrylate (PMMA), the NF experienced a slip due to decreased differential horizontal stress after arresting the propagating HF. The HF tip tends to open at the NF interface after intersection, causing the NF to slide and extend, thereby forming "hydro-wing" fractures and prohibiting the HF from crossing the NF interface (Seok Yoon et al. 2017). At lower horizontal stress difference and low approach angle, the plane along the NF will slip and shear notwithstanding the higher stimulated reservoir volume (SRV) (Hou et al. 2015). Wu and Olson (2014) considered bi-winged HFs intersecting with a NF, and results showed that one of the propagating HF wings was initially arrested at the NF interface, until build-up pressure inside the HF causes the shear failure at the NF as fluid flows into the two HF wings.

A stress shadow effect is produced when there is no near NF stress redistribution (Sesetty and Ghassemi 2012), as a result the HF propagates along the tip of the NF and high velocity fluid is diverted into the NF. The Nagel et al. (2012) continuum and discrete finite element modeling results show the effect of stress shadowing on the NF as it undergoes shear failure as the tip of the propagated single- and multiHF intersects with the NF. High perforation friction promotes diversion of the propagating multiple HFs into the $\mathrm{NF}$ and produces equal size of successive fractures notwithstanding the effect of stress shadow (Wu et al. 2012; Kresse et al. 2012). Taleghani and Olson (2013) observed that as the cement-fracture toughness threshold value falls below that of the rock matrix by $25 \%\left(G_{\text {frac }} / G_{\text {rock }}<0.25\right)$, the approaching HF fuses into the NF and extend the NF tip by shearing. Chen et al. (2014) suggested that shearing occurs due to decrease in friction force $\left(F_{\text {friction }}=\sigma_{\mathrm{n}} \times K_{\mathrm{f}}\right)$ and fracture overpressure $\left(P_{\sigma}\right)$. Thus, lower friction coefficient and low approach angle will encourage shearing at the NF interface (Chen et al. 2014). In the high-pressure, high-temperature (HPHT) KS tight sandstone reservoir, the results show that when the HF propagation pressure does not exceed the normal stress on the NF, the NF plane will likely shear and propagate the tip of the NF (Zhang et al. 2015). The auxiliary HF will likely propagate the tip of the shear-activated NF plane, which tends to create new interconnected fractures. Transverse fractures are likely to be created due to shear failure in the Marcellus shale (Aimene and Nairn 2014), and in weak and poorly consolidated sandstones (Ispas et al. 2012).

When the propagating HF is arrested at the NF and continues to propagate the tip of the NF with increase in length and width, we have a combined dilation and shearing behavior (Fig. 1g). In shale gas reservoirs, not all pre-existing NF can be reactivated with the propagation and dilation criteria (Song et al. 2014). Although direct crossing will be observed at high HF-NF approach angle $\left(60^{\circ}-90^{\circ}\right)$, but at low-tomedium approach angles and varying differential horizontal stresses, the HF is inclined to be arrested at a weakly bonded NF plane, or the HF can continue to propagate the tip of NF by dilation and shearing (Yildirim et al. 2018a; Zhou and Xue 2011; Nikam et al. 2016). The microseismic monitoring results in Williams-Stroud et al. (2012a, b) showed the reactivation of pre-existing NF by shearing and dilation by induced HF in well stimulation treatment. At low injection rate, low fluid viscosity, and low approach angles, the HF will tend to fuse into the NF to "expand" the NF and reactivates the NF (Chen et al. 2015; Nikam et al. 2016; Zhou et al. 2016), while at orthogonal angle, the NF opening and open-zone length decreases (Akulich and Zvyagin 2008). Fracture network with greater length and width will be generated.

Debonding (dilation) of the plane of the natural fracture prior to HF-NF intersection (Fig. 1h) was identified as a newly observed HF-NF interaction behavior. Further understanding of this reactivation of the NF prior to HF-NF intersection is of utmost importance before initiating hydrofracturing job. This will avert any operation failure and ensure maximum matrix stimulation optimization. The 
new interaction behavior was identified in Keshavarzi et al. (2012), where the NF debonding was observed around the near-tip of the approaching HF before intersecting with a cemented NF. The NF can fail and begin to shear or dilate even before the HF intersects with the plane due to the modified stresses (normal and shear stresses) near the propagating HF (Cheng et al. 2014a), thereby reactivating the NF even before the HF intersects the NF. The debonded zone length and position on the natural fracture, NF orientation, and the differential horizontal stress influences the reactivation of the NF during early phases prior to HF-NF intersection. $\mathrm{Bi}$-winged fractures may be created in this debonded area of the NF interface (Taleghani and Olson 2013). Taleghani and Olson (2011), Keshavarzi and Jahanbakhshi (2013), and Taheri-Shakib et al. (2016a) also observed the debonding of the cemented NF before the propagating HF intersects with the NF interface. This was induced by high tensile stress exerted at the HF tip as it propagates toward the interface at various approach angles $\left(30^{\circ}, 60^{\circ}\right.$ and $\left.90^{\circ}\right)$. A complex fracture network was created in Aimene and Nairn (2014) when the MPM was applied to laboratory investigation of $\mathrm{HF}-\mathrm{NF}$ interactions. Stress is generated around the HF tip as the HF approaches the NF, which will further induce stress change around the interface of the NF. This results in "opening" and debonding of the NF even before the propagating HF intersects with the NF (Zhou et al. 2015). In utilizing extended finite element method (XFEM), both cemented and uncemented NFs can get debonded (Taleghani and Olson 2011; Taheri-Shakib et al. 2016a) or shear even before interaction with growing multiple HFs. This was observed to be due to combination of high-shear and tensile stresses acting ahead of or near the HF tip.

\section{Other HF-NF interaction behavior}

A peculiar behavior observed during the HF-NF interaction is the bypass of the NF by a propagating HF (Fig. 1i). Olson et al. (2012) experimental results showed an induced HF of higher length bypassing a natural fracture of shorter length and propagate around it after intersecting it at an orthogonal angle. Fu et al. (2015a) investigated how a propagating HF intersects with pre-existing NF by assuming a three-dimensional (3D) plane. At orthogonal approach angle and NF with very low to no cement filling, a new HF-NF interaction behavior was observed. If the fluid injection pressure moderately exceeds the minimum horizontal stress of the in situ rock $\left(\sigma_{\mathrm{H}_{\min }}\right)$ the propagating HF will tend to open and create two front tips on intersection with the pre-existing NF. These front tips will advance around the NF, and the space between the tips will increase if the shear stress is too low to induce a fracture behind the front tips. The propagating HF tips will tend to later merge behind the NF interface and continue to propagate as a "unit" fracture, while the
NF plane disrupts the flow path. The approaching HF does not directly cross the NF interface, as this was observed to appear like an indirect-crossing behavior. In pre-existing NF with thin and very low cement filling, the NF interface will tend to shear after the propagating HF bypasses the NF interface in 3D space.

\section{Approach and investigation parameters}

\section{Methods of approach}

An overview of the numerical approach of investigating HF-NF interactions with special concentration on the mechanical models was discussed in Taleghani et al. (2016), where the linear elastic fracture mechanics (LEFM) is useful in modeling HF crossover or diversion after intersection with a pre-existing NF. A cohesive element approach is applicable in correlating the local fracture release rates to the far field stresses. Virtual fracture closure techniques (VFCT) and cohesive zone model (CZM) (Guo et al. 2017; Taleghani et al. 2018; Wang 2019) have shown credible results in simulating HF-NF interactions. Mesh-dependent parameters and unpredictability of the fracture propagation path are the most fundamental demerits of the CZM and VFCT. When variable length and sizes are integrated in the simulation modeling, the continuum damage mechanics (CDM) approach could be adopted to provide more accuracy. Phase field modeling method (McClure and Horne 2013; Wheeler et al. 2019) has proven to be a resourceful approach that can be utilized in investigating HF-NF interactions.

Kear et al. (2017) performed studies to describe the NF-HF interactions using 2D Eidsvold siltstone specimen experiment and plane-strain boundary element numerical hydraulic fracturing model (MineHF2D). In investigating the impact of interface properties on fracture propagation initiation, fracture path, and HF growth, Aimene et al. (2018) conducted a fully 3D anisotropic damage mechanics $(\mathrm{ADaM})$ model implemented with the material point method (MPM). The three (3) NF interface properties adopted are: weak interface model with very low interface stiffness, perfect/well-bounded/strong interface with very high interface stiffness, and the sliding/frictionless contact with zero viscosity using Coulomb friction model. Aimene and Nairn (2014) utilized a similar material point method (MPM) to investigate how multiple propagating HFs interact with preexisting NF. In Cheng et al. (2014a), a 3D displacement discontinuity method was used to describe how the HF growth intersection with $\mathrm{NF}$ (at $45^{\circ}$ and $90^{\circ}$ ), and the NF failure prediction at the interface could be attempted if results obtained is compared with the Mohr-Coulomb criterion. Nikam et al. (2016) integrated an advanced cohesive pore pressure (CPP) in finite element analysis (FEA) to describe the injection

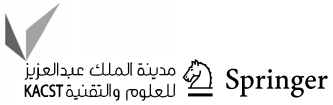


fluid behavior (Elwegaa et al. 2019) at HF-NF intersection. Cheng et al. (2014b) study was based on numerical and experimental analyses of cement block fracturing test with pre-existing fractures and validated the results with microseismic data from the lower Silurian Longmaxi shaly formation of Sichuan basin, China, to develop a new NF-HF interaction criterion.

The NF-HF interaction in a low-permeability fractured reservoir using a 3D DFN model was extensively discussed in Dershowitz et al. (2010), Bajestani and Osouli (2015) and Campbell et al. (2018). Some authors reported that HF propagation is influenced by properties and geometry of the pre-existing NF, in situ stress field, and the energy of the HF. Although this approach can be adopted in numerical modeling of NF-HF interactions for wells that lack seismic monitoring, some of its identified limitations are inability to estimate in situ stress, application in 3D plane (interconnectivity of NF and HF in 3D space), and unpredictability of HF properties and the NF geometry. Chen and Rahman (2015) developed novel artificial neutral networks (ANN) to explain the NF-HF interaction by mapping the interaction patterns, using back-propagation neutral network (BPNN) model and probabilistic neutral network (PNN) model. The ANN approach provides more real-time results because it is principally data-driven (Keshavarzi and Jahanbakhshi 2013). Less computational cost and lower time consumption is another major advantage ANN have over other numerical methods of HF-NF interaction studies.) Propagation of multiple HFs' interaction with induced and pre-existing natural fractures using extended finite element method (XFEM) (Mikaeili and Schrefler 2018; Milanese et al. 2018) was investigated and modeled by Taleghani and Olson (2011) and Wang et al. (2018c), while Ghaderi et al. (2018a) utilized Coupled DEM and XFEM.

The 2D DEM (Nagel et al. 2012; Li and Yang 2018; Zhao et al. 2019b), finite element method (FEM), and boundary element method (BEM) are some of the most-often adopted approach in numerical investigations of HF-NF interaction. The interaction between a hydraulically induced fracture and a natural fracture can also be numerically investigated using: (1) semi-analytical pressure-transient model in Laplace domain (Xiao et al. 2017); (2) Fast Lagrangian Analysis of Continua in 3D (FLAC3D) simulation model; (3) UDEC Universal Distinct Element Code (UDEC); (4) distinct element code (UDEC) model; (5) dual-lattice fully coupled hydro-mechanical hydraulic fracture simulator (Zhou et al. 2015; Pettitt et al. 2018; Zhao et al. 2018). HF-NF interactions in geothermal reservoirs were investigated by Riahi and Damjanac (2013) using a 2D DFN, where a decrease in DFN connectivity as the fracture density decreases was discovered. In considering a fully bonded interface and five (5) partially bonded interface experiments, Fu et al. (2015a) explained the effects of partially cemented NF on HF-NF interaction. In field-derived DFN explicit model of the HF-NF interaction, injection of highly compressible fluid was shown to create a more complex HF geometry than when less-compressible fluid was injected (Damjanac et al. 2010). The interaction behavior between NF and HF in lowpermeable and brittle hard rock can be simulated by either integrating a coupled DFN and dual-lattice DEM (Zhou et al. 2016), coupled lattice Boltzmann method (LBM) and DEM (Chen et al. 2018), a 2D Particle Flow Code (PFC2D) (Han et al. 2012; Seok Yoon et al. 2017; Yildirim et al. 2018a), Particle Flow Code in 3D (PFC3D) (Lee et al. 2018), a bonded particle method (BPM) (Zhang et al. 2018), and a smooth joint contact method (SJM). Chuprakov et al. (2013) openT model, and Carbonell and Detournay (1995) semi-analytical exact elastic solution of finite dislocation was used to predict the NF reactivation point after intersecting with a propagating HF. A 2D displacement discontinuity method (DDM) (Wu et al. 2012; Moradi et al. 2017; Kresse et al. 2012; Tang et al. 2018) was adopted to investigate the stress shadow created during HF-NF interaction.

The foremost experimental studies of HF-NF interaction were conducted by Blanton (1982, 1986), Warpinski and Teufel (1987), Warpinski (1991), Warpinski et al. (1993), and Renshaw and Pollard (1995). Warpinski and Teufel (1987) conducted their experiment in a true triaxial with Coconino sandstones containing pre-existing microfractures. In Beugelsdijk et al. (2000) scaled laboratory experiment to investigate $\mathrm{HF}-\mathrm{NF}$ interaction, $0.3 \mathrm{~m}$ cubic model blocks composed of Portland cement are used in a triaxial pressure machine. The HF growth was observed by the authors to start retarding upon intersection with an opened NF. In the experimental study of Zhou and Xue (2011), a thin Teflon sheet was inserted in-between $0.3 \mathrm{~m}$ cubic model blocks inside a triaxial pressure machine, and the blocks are composed of a mixture of cement and fine sand. The authors' results showed the influence of NF maturity and in situ stress contrast on propagating HF geometry. Olson et al. (2012) utilized $1 \mathrm{ft}$ cubes of hydrostone (gypsum cement) and glass sides (to model NFs) to experimentally investigate HF interaction with naturally cemented NFs. In experimental work of Cheng et al. (2014b), $0.3 \mathrm{~m}$ cubic blocks composed of cement and quartz sand were used in a triaxial system to show crossing behavior. Sandstone blocks from an outcrop of the Kenshen sandstone formation in Tarim Oil Field were utilized by Yang et al. (2016) to investigate HF-NF interaction in a poly-axial stress frame loaded in a strike-slip stress regime to show arrest and NF reactivation behavior. In approach by Mighani et al. (2018a), cylindrical blocks of poly(methyl) meta acrylate (PMMA) and Solnhofen limestone were used for sliding experiments to investigate HF-NF interaction under triaxial stress condition.

The semi-circular bending (SCB) (Lee et al. 2015; Wang et al. 2013, 2018b) experimental test was conducted to 
observe how HF propagates in weak and strong cementbonded NF. The SCB test is efficient in testing small-sized and subsurface rock samples. Lee et al. (2015) utilized naturally fractured Marcellus shale rocks to conduct unconfined compressive strength (UCS) and SCB tests. Fatahi et al. (2017) and Wang et al. (2018b) coupled numerical and experimental approach to study propagating HF interaction with pre-existing NF. The authors' experimental results were converted to field scale using numerical methods. This provided more reliable results. The HF-NF interaction study results in a permeable pre-existing NF with a fingerlike crack were shown to have substantial insignificant effect of poroelasticity on changes in injected fluid pressure in the using Green's function approach (Sarvaramini and Garagash 2016). Paryani et al. (2016) also combined a pseudo 3D asymmetrical frac design with 2D strain map to analytically and numerically determine the influence of frac design parameters. The authors concluded that the most influential parameters affecting the longer side of asymmetric fracture wing are drainage area, fracture height, and reservoir permeability, while the influential parameters affecting the shorter side of asymmetric fracture wing are stress gradient, fracture height, and reservoir permeability. In Yildirim et al. (2018b) triaxial test experiment, shale and coal blocks were tested to investigate fracture initiation location and interaction between pre-existing NFs in the blocks. Solnhofen limestone was investigated under triaxial stress conditions in Mighani et al. (2018b) using fault Gouge insertion and DCDT displacement transducer. Hydrofracturing was adopted for pre-conditioning during block cave mining operation to enhance the cavability and fragmentation sizes, and the HF was shown to propagates along the horizontal plane in cave mining (He et al. 2015).

Microseismic data from the field are an efficient analytical method to provide valuable data points to validate HF-NF interaction behavior identified from other sources (Maity and Ciezobka 2018; Williams-Stroud et al. 2012a, c). Microseismic data from Eagle Ford shale are used to validate $\mathrm{HF}-\mathrm{NF}$ interaction studies from an improved frac design using strain maps to estimate the permeability of proppant volume and its importance (Ouenes et al. 2015). A sequential, hierarchical multi-scale approach was combined with GEOS HPC geoscience framework by Johnson et al. (2013) to model multi-scale fracture network created during HF-NF interaction. A coupled seismo-hydro-mechanical simulation was later adopted to investigate how propagation of bi-3D hydraulic fractures. A novel fully coupled 3D GEOS simulation code was developed by Fu et al. (2015a) to model HF-NF interaction in 3D space. A 4D near-wellbore Geomechanics simulation of HF-NF interaction was developed by Zhang et al. (2015) in the high-pressure, high-temperature (HPHT) KS tight sandstone reservoir, Tarim basin, China. As the effective fracture length increases, there is a rise in borehole internal pressure, which raises the possibility of identifying the fracture initiation point (Tarokh et al. 2016). Wellbore strengthening as extensively discussed in Feng and Gray (2017), proppant transportation and placement are also greatly influenced by presence of NFs in hydrofracturing process. The analytical composite criterion was utilized by Zhao et al. (2019a) to predict crossing and NF reactivation behavior simultaneously.

\section{Influence of test parameters}

The interaction behavior generated before or after a propagating hydraulic fracture intersects with a pre-existing natural fracture is dependent on certain test parameters adopted for the investigation. Some dominant factors influencing HF-NF interaction behavior have been extensively studied and identified as: approach angle, horizontal differential stress, rock and natural fracture properties, and HF fluid properties (Medlin and Fitch 1988). From sensitivity analysis results, Xiao et al. (2017) concluded that the distance between NFs and the well, distance between NFs and HFs, NF orientation, NF half-length, HF half-length, number of NFs, flow regimes within the HF are significant parameters in understanding NF-HF interactions. Bajestani and Osouli (2015) and Yao et al. (2018) concluded that the parameters that influences HF-NF interactions are: (1) arrest of HF because of high-water flow into the NF network; (2) increase in the sets of NFs at an orthogonal approaching angle to the propagating $\mathrm{HF}$, resulting in less water flowing into the NF network and crossing of the NF by the HF; (3) arrest of HF can be aided by reduction in injection rate and pumping pressure, because of high in situ stress around the rock matrix. The approach angle is the angle at which a propagating HF intersects a pre-existing natural fracture or fault. Chen and Rahman (2015) showed that crossing of the NF by HF was aided by high differential horizontal stress $(\Delta \sigma)$ and high approach angle. Zhou et al. (2015) and Beugelsdijk et al. (2000) reported that HF approach angle, natural fracture permeability, fluid injection rate, stress anisotropy, fluid injection viscosity (Fakoya and Shah 2016), and natural fracture cohesion are predominant factors affecting HF-NF interaction. The DFN and PFC2D results (Yildirim et al. 2018a) show that differential horizontal stress regulates the $\mathrm{HF}$ growth and propagation despite the omnipresence of NF in the NF-HF interaction and HF propagation. A high differential horizontal stress will result in direct crossing of the NF by a growing HF, while arrest of the HF will be expected at low differential horizontal stress.

The influence of pre-existing NF on Eagle Ford shale mechanical properties was investigated by $\mathrm{Hu}$ et al. (2014). The authors concluded that approaching angle $(\theta)$ can alternate HF propagation pattern and affect the in situ-rock's mechanical and elastic properties. The effect of intersection 
angle, in situ stresses, rock and fracture properties, injection rate, and fluid viscosity on HF-NF interaction was investigated by Kear et al. (2017) and Chen et al. (2015). Although the fracture geometry evolution, injection pressure, and crossing mechanisms may differ, the HF crossing behavior was in concurrence with the crossing criterion (Renshaw and Pollard 1995). Larger-sized NF tends to easily form complex-shaped HF and increase the formation of fracture networks (Dong et al. 2018). Differential horizontal stress exceeding $14 \mathrm{MPa}$ will form a single interconnected straight fracture, without any effect on the shape of the HF. Chen et al. (2014) concluded that approach angle has greater influence on shear failure during HF-NF interaction than differential horizontal stress. Ultrasonic pulse velocity (UPV) measurement was used by Wang et al. (2017) to study the HF-NF interaction, and they concluded that low in situ stress and high injection rate creates a more complex fracture network after intersection. Moradi et al. (2017) attributed length and spacing of the NF, and approach angle to be influential in determining the distance between the tip of the NF and the propagating HF. Huang et al. (2014) proposed that increase in fracture intensity (relatively low HF spacing, $<30.48 \mathrm{~m}$ ) will cause the propagating HF to always terminate and get arrested at the NF. The effects of approach angle, strength of NF plane, differential horizontal stress, and injection point distance to the NF interface, on the HF-NF interaction was also investigated by Zhu et al. (2018). Hou et al. (2015) attempted to categorize the factors influencing HF-NF interactions into controllable factors and uncontrollable factors. The pump rate, and viscosity of fracturing fluid are controllable factors, while the rock mechanical properties, and in situ stress differences are uncontrollable factors. Ben et al. (2012) also agreed on the importance of NF orientation and location on HF-NF interaction. The mineral grain distribution and pore density, which characterizes the permeability response, could significantly influence the pre-existing NFs (Schwartz et al. 2019).

In adopting an enhanced 2D displacement discontinuity method (DDM) to study the effect of stress shadow in complex HF-NF interactions, Kresse et al. (2012) observed that stress shadow effect exists in multiple HFs, and this effect dwindles with increase in ratio of fracture spacing to fracture height. In simulation results obtained by Kamali and Ghassemi (2019) using a new DFIT simulation model, the injection pressure profile, path of the fracture propagation, and interference with post shut-in pressure are some of the effects of NF on HF propagation. He et al. (2015) reported that the NF dip angle, rock tensile strength, and treatment parameters have significant effect on the HF-NF intersection and influences the HF-NF interaction behavior in block cave mining. The numerical results contradict most HF-NF interaction studies, as a propagating HF may be temporarily arrested at the NF interface at high approach angle and small dip angles, but this is only observed in block cave mining. Changes in injection rate and injected fluid viscosity were investigated by Gil et al. (2011), and the results obtained show the possibility of tensile failure within a naturally fractured reservoir increases with higher injection rates. On the other hand, lower injection rate was observed to encourage shear failure near the injection well. Daneshy (2019) discussed that changes in injection fluid pressure, differential horizontal stresses, magnitude of net fracture pressure, and 3D NF inclination angle are some of the factors affecting HF-NF interactions. Also, a bidirectional stepping behavior of sublinear fracture network was observed when an obtuse angle $\left(135^{\circ}\right) \mathrm{NF}$ orientation was formed, which led to arrest of the HF. The HF was observed to cross the NF when the $\mathrm{NF}$ orientation is an acute angle $\left(45^{\circ}\right)$.

\section{New observations and their implications}

\section{Assessment of the methods of investigating HF-NF interactions and its implications}

In Fig. 2, we present already identified and newly observed interaction behavior between hydraulic fracture and preexisting natural fracture available in scientific publications over the past 50 years in the data from Kolawole and Ispas (2019b). The possible HF-NF interaction processes are listed on the ordinate, while the number of published scientific articles is listed on the abscissa.

The bypass of the NF by propagating HF is identified to be the least reported interaction behavior irrespective of the method of approach adopted, while HF crossing of the NF without NF dilation, and the NF reactivation by shear, are the most-often reported interaction behavior. In Fig. 3, we present published articles between 1963 and 2018 on HF-NF interactions, and the variations in methods of approach. This shows the potential effect of methods of approach over time. In our spatiotemporal analysis, we observed that the numerical modeling is the most dominant method of approach, while the analytical method appears to be least utilized method. The analytical method is most often adopted in combination with numerical or experimental methods. We observed there has been less focus on experimental investigations of HF-NF interactions over the past decade when compared to the HF-NF interaction numerical method of approach.

\section{Influence of fracture network}

Here, we define fracture array as a single- or multiple-pair of a propagating $\mathrm{HF}$ and a pre-existing NF (HF-NF); and fracture network as a pattern of fracture arrays. The fracture 
Fig. 2 Bar graph showing identified HF-NF interaction behavior and variations in methods of approach

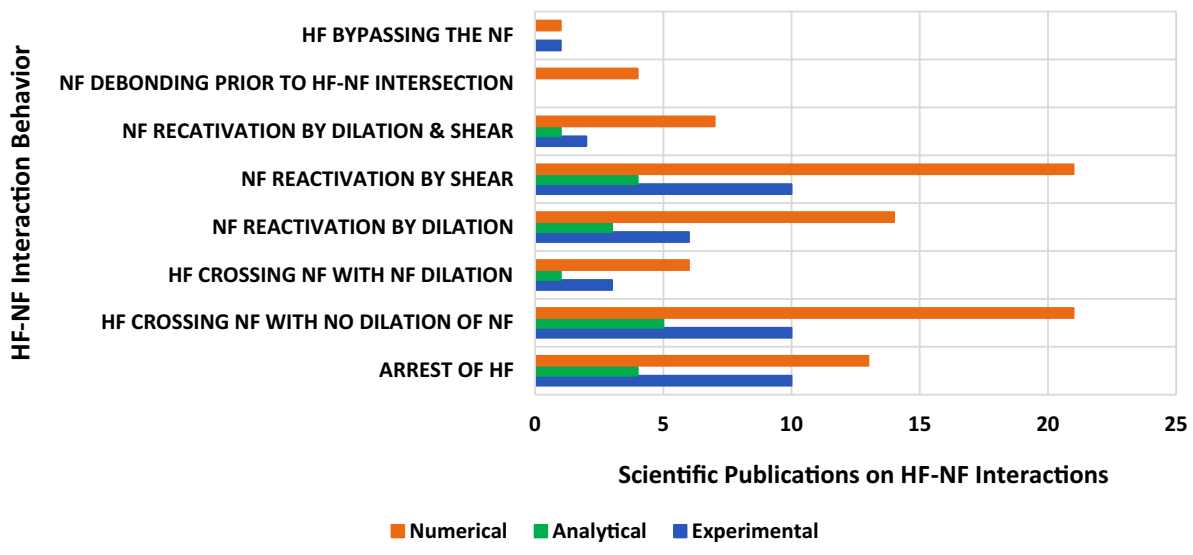

2012; Keshavarzi et al. 2012; Wu et al. 2012; Kresse et al. 2012; Zhou et al. 2015, 2016), is a branching phenomenon likely caused by competing dilation-favorable and crossing-favorable parameters acting on the NF interface. This will not likely form a fault line because of alternating very low-to-moderately low approach angles that dominates the HF-NF interactions in addition to shear and dilation.

Some of the long-term impacts of the HF-NF interactions on the reservoir are:

1. Creation of faults.

2. Increase in permeability of the natural fractures.

3. Local stress redistribution in the reservoir along the created faults (stress rotation).

F. 3 Bar graph showing number of published articles between 1963 and 2019. This chart shows variations in methods of approach over time

networks created by HF-NF interactions can be grouped into the four (3) categories, namely:

(a) Orthogonal fracture network.

(b) Sub-orthogonal fracture network.

(c) Linear-to-sublinear fracture network.

The orthogonal fracture network (Fig. 4a) is characterized by high approach angle $\left(90^{\circ}\right)$, crossing interaction behavior, and will likely create a coherent fault line (longer faults). In sub-orthogonal fracture network (Fig. 4b), medium-tohigh approach angles and high likelihood of non-crossing interaction behavior are the prevailing features. It is less likely to create a coherent fault line. In the linear-to-sublinear fracture networks, two (2) forms of side-stepping of the NF plane can be observed: (a) unidirectional stepping, (b) bidirectional stepping. Although low approach angles mostly dominate the unidirectional stepping (Fig. 4c) and bidirectional stepping (Fig. 4d), the nature of the faults they create differentiates them. The unidirectional stepping is a branching phenomenon most likely to evolve in a coherent fault line (smaller faults) due to dominant shear and dilation HF-NF behavior. The bidirectional stepping (Ben et al.

\section{Proposed real-time monitoring of HF-NF interactions}

In this section, we consider the possibility of HF-NF interactions monitoring in real time on the field from reviewed articles using a pre-frac test approach. A pre-frac (mini-frac) test is a typical injection test performed in the field without using a proppant before the actual hydraulic fracture treatment is conducted. The breakdown pressure is the pressure observed when the hydraulic fracture is initiated after the formation is cracked. This formation breakdown pressure is influenced by tensile strength of the in situ rock, formation pore pressure, and the minimum horizontal stress $\left(\sigma_{\mathrm{H}_{\min }}\right)$. The breakdown pressure must exceed the minimum horizontal stress around the wellbore, and the tensile strength of the in situ rock. As the propagating hydraulic fracture grows, the fluid in the hydraulic fracture delays before it reaches the fracture tip. This phenomenon is known as fluid lag (Jeffrey 1989; Green et al. 2017; Napier and Peirce 2014). The fluid lag distance $(D)$ is the region between the invaded and uninvaded (frontal) segment of the propagating hydrofracturing fluid, while the distance between the borehole and the tip of the propagating fracture tip is known as fluid lag length $\left(L_{\mathrm{f}}\right)$. 
A

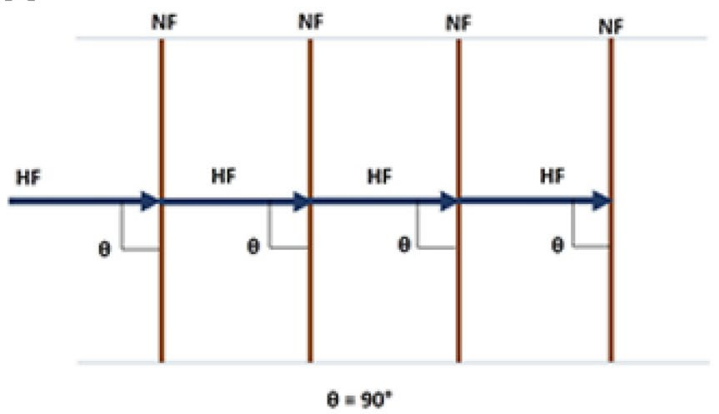

C

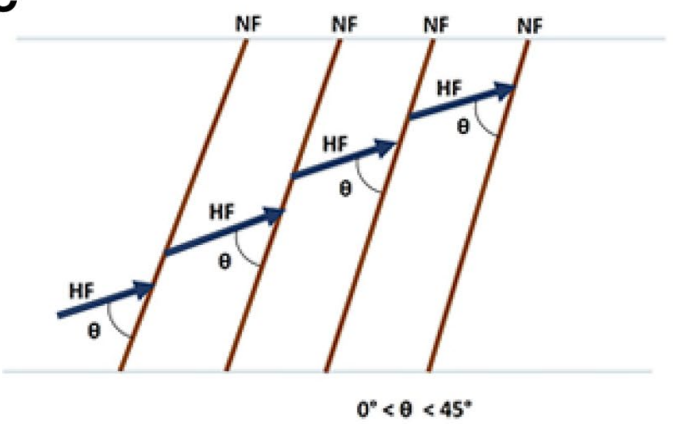

B

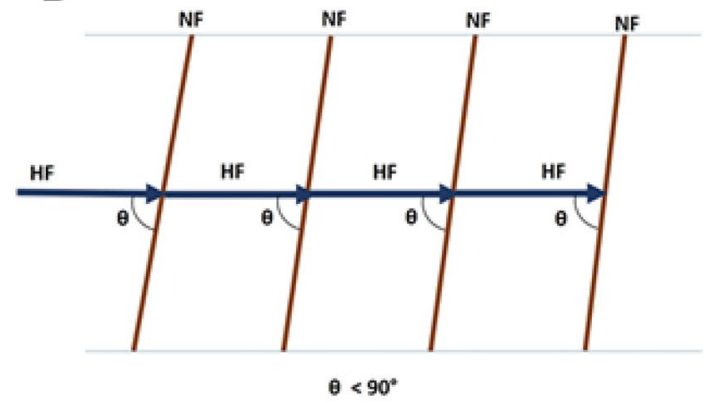

D

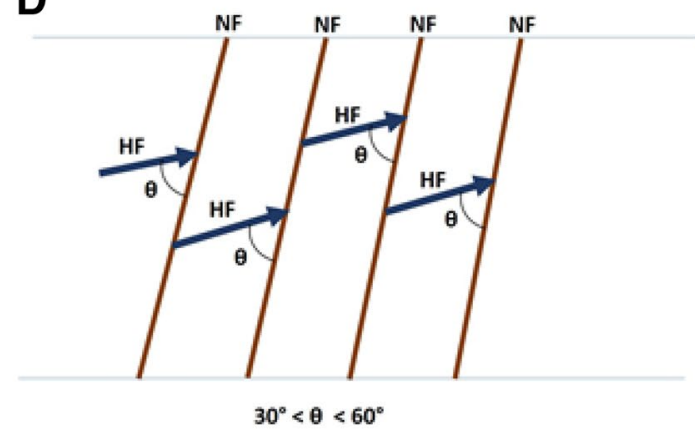

Fig. 4 Fracture networks created due to HF-NF Interactions featuring array length of 4; a orthogonal fracture network, b sub-orthogonal fracture network, c linear-to-sublinear fracture network (unidirectional stepping), d linear-to-sublinear fracture network (bidirectional stepping)

Since the fluid lag region will provide a negative value to the stress intensity factor, it is incorporated as an apparent fracture toughness value and presented as:

$K_{I \text { - fluid pressure }}=K_{\mathrm{IC}}+K_{\mathrm{IC}-\mathrm{lag}}$

Assuming the fluid lag region is equal to the formation pressure, for a penny-shaped propagating hydraulic fracture, Eq. (11) can be expressed in terms of fluid lag distance $(d)$ (Jeffrey 1989) as:

$d=R-\sqrt{R^{2}-\left(\frac{2 P_{\mathrm{w}} R-K_{\mathrm{IC}} \sqrt{\pi R}}{2\left(\sigma_{\mathrm{tip}}+P_{\mathrm{w}}\right)}\right)^{2}}$

When fracture toughness of the in situ rock is zero, the maximum fluid lag distance is expressed as:

$d=R\left(1-\sqrt{1-\left(\frac{P_{\mathrm{w}}}{\left(\sigma_{\text {tip }}+P_{\mathrm{w}}\right)}\right)^{2}}\right)$

The maximum fluid lag distance due to apparent fracture toughness $K^{\mathrm{Lf}}$ for pressurized penny-shaped hydraulic fracture (Eq. 14) is presented in Fig. 5 as:
$K_{\mathrm{IC}}^{L_{\mathrm{f}}}=2 \sigma_{\text {tip }} \sqrt{\frac{R}{\pi}\left(\frac{P_{\mathrm{w}}}{P_{\mathrm{w}}+\sigma_{\text {tip }}}\right)}$

Advani et al. (1993) proposed a 3D geometry and fluid lag-fracture fluid pressure sensitivity phenomenon. In the

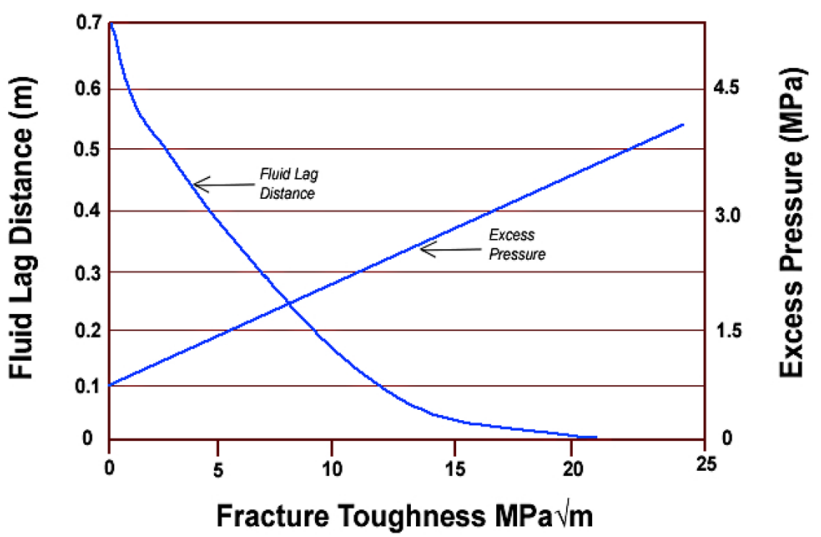

Fig. 5 Variation of fluid lag distance and effective pressure with fracture toughness for a typical pre-frac test. Modified after Jeffrey (1989) and McLennan and Potocki (2013) 
field case considered, the results showed that pressure distribution around the tip of the propagating HF influences stress intensity factor near the tip of that fracture. This strong influence of the pressure exerted around the fracture tip creates a fluid lag during hydrofracturing process. In the sensitivity analysis of varying amounts of fluid lag created, the results validated the fluid lag hypothesis that a maximal amount of fluid lag will result in pronounced decrease in pressure required for fracture propagation during hydraulic fracturing. Due to normal and shear stress acting at the intersection between HF and NF, the NF permeability can be facilitated by dilation and shearing along the natural fracture at HF-NF intersection point (Taheri-Shakib et al. 2018). The presence of NF can cause slowdown the propagation of $\mathrm{HF}$, which would increase the fluid lag and delay the leakoff (Ghaderi et al. 2018b). In hydrofracturing process, the fluid injection pressure decreases as the hydraulic fracture propagates through the formation after initiating the fracture. Green et al. (2017) concluded that this reduced pressure can be due to intersection between injected fracturing fluid and a pre-existing NF, and results in fluid injection pressure trailing the fast-paced fracture growth. The fluid lag phenomenon will be created, which delays the formation from receiving the effect of injected fluid pressure and curtail the fracture propagation. The HF This fluid lag effect due to $\mathrm{HF}-\mathrm{NF}$ intersection will be expected to produce complex interactions behavior. There is a significant disparity in fluid injection pressure-time history and the fracture growth path, between a propagating HF intersecting with a pre-existing NF having a fluid lag and minimal fracture toughness, and a HF intersecting with/without a pre-existing NF having no fluid lag and high fracture toughness (Green et al. 2017; Napier and Peirce 2014). The possible interaction behavior which could infer varying pressure fluid injection and time responses are:

(a) Propagating fracture may be temporarily arrested by the pre-existing NF

(b) The propagating fracture may directly cross the preexisting NF

(c) The propagating fracture may not intersect with a preexisting NF

Increase in number of pre-existing NFs will increase the complexities of HF-NF interaction behavior and extend the net fracture pressure (NFP) (McLennan and Potocki 2013). The net fracture pressure is the resistance effect to fracture propagation. There is increase in fracture closure stress as the propagating HF intersects with pre-existing. As the HF growth is slowed down by the pre-existing NF, the fluid lag and time is increased, while a decrease in pressure will be expected. The increase in net fracture (NFP) gradient will tend to increase the in situ stress, and thereby promoting the likelihood of complex HF-NF interaction behavior and fluid lag to be created (Potocki 2012). Yang (2008) investigated how the presence of pre-existing natural fractures affects formation breakdown pressures recorded during pre-frac tests. During the study, about 1000 formation breakdown pressures (between 2000 and 6000 psi) was considered in the Codell formation, Wattenberg field, Colorado, USA. The formations in Wattenberg field are characterized by tight sand or low-permeability carbonates. The formation breakdown pressures recorded was mapped with well locations in the Wattenberg field near a pre-existing fault (NF), and wells far from faults. Observations from the results validated the author's prediction of low breakdown pressures recorded in oil and gas wells located near pre-existing NFs, and high breakdown pressures recorded in wells far from pre-existing NFs. In study conducted by Daneshy (2007), the results showed a significant decrease in fluid pressure in the fracture and the fracture width as the HF propagates after fracture is initiated. The author reported that the varying bottomhole pressures recorded was due to the presence or removal of interference (NF) to the flow of fluid inside the propagating fracture. This interference will eventually increase fluid lag, and the time for the fluid inside the propagating fracture to connect with the reservoir fluid. Lecampion et al. (2004) proposed how fracture orientation, fracture volume, and efficiency of hydrofracturing treatment can be estimated in real time from tilt data obtained from tiltmeter. Xu et al. (2018) utilized displacement discontinuity method (DDM) and finite volume method (FVM) to investigate the effect of fluid leak-off on HF-NF interaction, and the HF-NF behavior due to fluid injection volumes and injection times. The authors concluded that crossing behavior can be expected during leak-off tests at high approach angle, high interfacial friction, and high injection rates.

In Fig. 6, we presented a 3D schematic illustration of interactions between propagating hydraulic fracture and preexisting natural fracture during a pre-frac test. In considering the stress contrast in the formation, fracture geometry, and other parameters influencing $\mathrm{HF}-\mathrm{NF}$ interactions, we propose that real-time HF-NF interactions can be monitored on the field during a pre-frac test. Cementation along the pre-existing natural fracture can be elliptical, rectangular, circular, or microfractures. We present three possible scenarios, and we assumed a non-homogenous cementation along the NF: (1) momentary arrest of propagating HF at the preexisting NF with NF reactivation by shearing or dilation; (2) direct crossing of the pre-existing NF by propagating HF; and (3) non-interaction of propagating HF with preexisting NF. In the first scenario, assuming a low approach angle and a pre-existing NF with weak cement filling, the propagating $\mathrm{HF}$ is expected to be temporarily "restricted" at the NF plane before the NF is reactivated by dilation and/or shearing. The propagating HF later continues its growth path

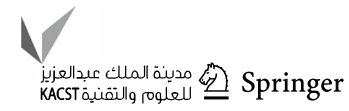




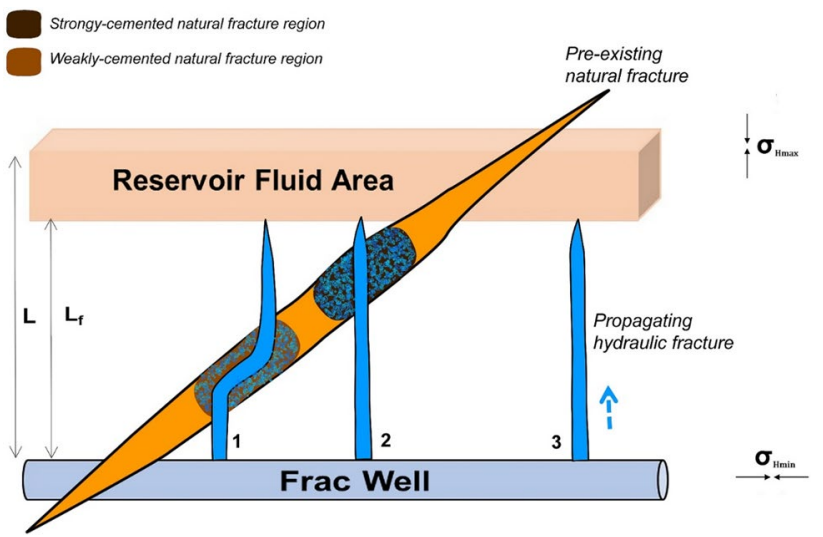

Fig. 6 3D Schematic description of interactions between propagating hydraulic fracture and pre-existing natural fracture during pre-frac test. $L_{\mathrm{f}}$ : Fluid lag length; $L$ : fracture half-length; NF: pre-existing natural fracture; HF: propagating hydraulic fracture; $\sigma_{\mathrm{H}_{\max }}$ : maximum horizontal stress; $\sigma_{\mathrm{H}_{\min }}$ : minimum horizontal stress. Modified after Advani et al. (1993)

until it connects with the reservoir fluid. The fluid lag and time for the fluid pressure inside the propagating fracture to be transmitted to the reservoir fluid area is expected to be highest in the first scenario when compared to the other two scenarios.

The propagating HF will be expected to directly cross the NF without a significant delay in the second scenario as much as will be expected the first scenario, while assuming a high approach angle exists, and the pre-existing NF has a strong cement filling. We expect the fluid lag and time for the fluid pressure inside the propagating fracture to be transmitted to the reservoir fluid area to be minimal in the second scenario when compared to the first scenario. For the third scenario, we expect the propagating HF to connect with the reservoir fluid area without interacting with a pre-existing NF. The pre-existing NF is assumed not to be in proximity of the propagating HF. Therefore, we expect zero fluid lag and no delay in transmission of the fluid pressure inside the propagating fracture to the reservoir fluid area.

\section{Conclusions and recommendations}

In this paper, we presented an up-to-date review of numerical, analytical and experimental investigations into the interactions between a propagating hydraulic fracture (HF) and the in situ natural fractures (NF) over the past 5 decades. Subsequently, the most dominant and newly observed HF-NF interaction behavior is also provided.

Assessment of the methods of approach (numerical, analytical and experimental) shows that: (a) Numerical modeling and simulations are the most popular approach in investigating HF-NF interactions. There has been less focus on experimental investigation of HF-NF interactions over the past decade when compared to HF-NF interaction numerical approach.

(b) The two (2) most dominant HF-NF interaction behaviors are the crossing of the natural fracture by a propagating hydraulic fracture, and the natural fracture reactivation by shearing.

(c) The approach angle, horizontal differential stress, in situ rock and natural fracture properties, and hydraulic fracturing fluid properties (injection pressure rate, viscosity, etc.) are the dominant factors influencing the interaction between propagating hydraulic fractures and pre-existing natural fractures.

The observational and quantitative analyses of the fracture networks created due to interactions between hydraulic fracture and natural fractures reveal that the fracture network can be categorized into:

(a) Orthogonal fracture network

(b) Sub-orthogonal fracture network

(c) Linear-to-sublinear fracture network (which can be either unidirectional stepping or bidirectional stepping of the NF)

We propose the concept of monitoring HF-NF interactions in the field during a pre-frac test using three scenarios. We envisage that the presence of a pre-existing natural fracture could retard a propagating hydraulic fracture, which would significantly increase the fluid lag and delay leak-off.

Having identified the outstanding and persistent problems related to interactions between hydraulic fractures and natural fractures, we propose the following recommendations for further research:

(a) Coupled experimental and numerical HF-NF interaction studies to provide more comprehensive and realistic results to better understand how hydraulic fracture interact with natural fractures.

(b) Most studies are limited to "HF-NF-HF" fracture network, while field observations have shown the occurrence of fracture networks with greater array lengths. To better understand the overall evolving fracture network and their implications, there is need to increase the array length in numerical models to account for hydraulic fracture interactions with multiple pre-existing natural fractures in spatiotemporal scales.

(c) We recommend further studies on the influence of fracture fluid pressure, fluid geochemistry, and temperature in the reactivation mechanics of pre-existing natural 
fractures during interactions with propagating hydraulic fractures.

(d) We recommend coupling of experimental approach and advanced numerical models to further investigate bypass of the NF by propagating hydraulic fracture at non-orthogonal approach angles in 3D geometry.

(e) We recommend investigations on the effects of proppant transport and placement, and fracture initiation location on the HF-NF interaction behavior. Furthermore, we also recommend studies on the impacts of such behavior on frac flowback and produced water volume.

\section{Compliance with ethical standards}

Conflict of interest The authors declare that they have no conflict of interest.

Open Access This article is distributed under the terms of the Creative Commons Attribution 4.0 International License (http://creativeco mmons.org/licenses/by/4.0/), which permits unrestricted use, distribution, and reproduction in any medium, provided you give appropriate credit to the original author(s) and the source, provide a link to the Creative Commons license, and indicate if changes were made.

\section{References}

Advani SH, Lee TS, Dean RH, Pak CK, Avasthi JM (1993) Consequences of fracturing fluid lag in three-dimensional hydraulic fractures. Soc Pet Eng. https://doi.org/10.2118/25888-MS

Agrawal S, Shrivastava K, Sharma MM (2019) Effect of shear slippage on the interaction of hydraulic fractures with natural fractures. Soc Pet Eng. https://doi.org/10.2118/194361-MS

Aimene YE, Nairn JA (2014) Modeling multiple hydraulic fractures interacting with natural fractures using the material point method. Soc Pet Eng. https://doi.org/10.2118/167801-MS

Aimene Y, Hammerquist C, Nairn JA, Ouenes A (2018) 3D anisotropic damage mechanics for modeling interaction between hydraulic and natural fracture planes in a layered rock- application to eagle ford and Wolfcamp. In: Unconventional resources technology conference. https://doi.org/10.15530/URTEC-2018-2902985

Akulich AV, Zvyagin AV (2008) Interaction between hydraulic and natural fractures. Fluid Dyn 43:428-435. https://doi.org/10.1134/ S0015462808030101

Ayalew L, Yamagishi H, Reik G (2004) Ground cracks in Ethiopian Rift Valley: facts and uncertainties. Eng Geol 75(3-4):309-324. https://doi.org/10.1016/j.enggeo.2004.06.018

Bajestani BM, Osouli A (2015) Effect of hydraulic fracture and natural fractures interaction in fracture propagation. In: International society for rock mechanics and rock engineering

Ben Y, Miao Q, Wang Y, Shi G (2012) Effect of natural fractures on hydraulic fracturing. in: International society for rock mechanics and rock engineering

Bertrand L, Géraud Y, Le Garzic E, Place J, Diraison M, Walter B, Haffen S (2015) A multiscale analysis of a fracture pattern in granite: a case study of the Tamariu granite, Catalunya, Spain. J Struct Geol 78:52-66. https://doi.org/10.1016/j.jsg.2015.05.013

Beugelsdijk LJL, de Pater CJ, Sato K (2000) Experimental hydraulic fracture propagation in a multi-fractured medium. Soc Pet Eng. https://doi.org/10.2118/59419-MS

Blanton TL (1982) An experimental study of interaction between hydraulically induced and pre-existing fractures. Soc Pet Eng. https://doi.org/10.2118/10847-MS

Blanton TL (1986) Propagation of hydraulically and dynamically induced fractures in naturally fractured reservoirs. Soc Pet Eng. https://doi.org/10.2118/15261-MS

Campbell W, Wicker J, Courtier J (2018) Natural and hydraulic fracture density prediction and identification of controllers. In: Unconventional resources technology conference. https://doi. org/10.15530/URTEC-2018-2934611

Carbonell R, Detournay E (1995) Modeling fracture initiation and propagation from a pressurized hole: a dislocationbased approach. American Rock Mechanics Association, ARMA-95-0465

Celleri HM, Serebrinsky SA, Sánchez M (2018) Coupled simulation of the interaction of a hydraulic fracture with a natural fracture. American Rock Mechanics Association

Chen P, Rahman MM (2015) A novel approach to predict interaction between hydraulic fracture and natural fracture using artificial neural networks. Soc Pet Eng. https://doi.org/10.2118/17614 3-MS

Chen P, Rahman MM, Sarma HK (2014) Interaction between hydraulic fracture and natural fracture- a new prediction model by adaptive neuro-fuzzy inference system (ANFIS). Soc Pet Eng. https ://doi.org/10.2118/171927-MS

Chen Z, Jeffrey RG, Zhang X, Kear J (2015) Finite element simulation of a hydraulic fracture interacting with a natural fracture. Soc Pet Eng. https://doi.org/10.2118/176970-MS

Chen Z, Yang Z, Wang M (2018) Hydro-mechanical coupled mechanisms of hydraulic fracture propagation in rocks with cemented natural fractures. J Pet Sci Eng 163:421-434. https://doi. org/10.1016/j.petrol.2017.12.092

Cheng W, Jin Y, Chen M, Xu T, Zhang Y, Diao C (2014a) A criterion for identifying hydraulic fractures crossing natural fractures in 3D space. Pet Explor Dev 41(3):371-376. https://doi. org/10.1016/S1876-3804(14)60042-2

Cheng W, Jin Y, Chen Y, Zhang Y, Diao C, Wang Y (2014b) Experimental investigation about influence of natural fracture on hydraulic fracture propagation under different fracturing parameters. In: International society for rock mechanics and rock engineering

Chuprakov D, Melchaeva O, Prioul R (2013) Injection-sensitive mechanics of hydraulic fracture interaction with discontinuities. American Rock Mechanics Association, ARMA-2013-252

Clark JB (1949) A hydraulic process for increasing the productivity of wells. Soc Pet Eng. https://doi.org/10.2118/949001-G

Damjanac B, Gil I, Pierce M, Sanchez M, Van As A, \& McLennan J (2010) A new approach to hydraulic fracturing modeling in naturally fractured reservoirs. American Rock Mechanics Association

Daneshy AA (2007) Pressure variations inside the hydraulic fracture and their impact on fracture propagation, conductivity, and screenout. Soc Pet Eng. https://doi.org/10.2118/95355-PA

Daneshy A (2019) Three-dimensional analysis of interactions between hydraulic and natural fractures. Soc Pet Eng. https://doi. org/10.2118/194335-MS

Dershowitz WS, Cottrell MG, Lim DH, Doe TW (2010) A discrete fracture network approach for evaluation of hydraulic fracture stimulation of naturally fractured reservoirs. American Rock Mechanics Association

Dong H, Zhang G, Liu S, Nie Y, Yang X, Zhuang J (2018) Influence of multiple natural fractures on hydraulic fracture propagation

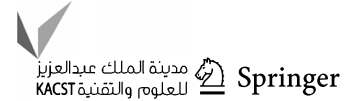


in fractured reservoir. American Rock Mechanics Association, ARMA-2018-917

EIA (2018) Short-term energy outlook (STEO). US Department of Energy Information Administration. https://www.eia.gov/outlo oks/steo/pdf/steo_full.pdf

Einstein HH, Dershowitz WS (1990) Tensile and shear fracturing in predominantly compressive stress fields-a review. Eng Geol 29(2):149-172. https://doi.org/10.1016/0013-7952(90)90004-K

Elwaziry Y, Soliman MY (2018) Diagnostic testing and analysis of hydraulically fractured dual-porosity formations. Soc Pet Eng. https://doi.org/10.2118/189881-MS

Elwegaa K, Emadi H (2018) The effect of thermal shocking with nitrogen gas on the porosities, permeabilities, and rock mechanical properties of unconventional reservoirs. Energies 11:2131. https ://doi.org/10.3390/en11082131

Elwegaa K, Emadi H, Soliman M, Gamadi T, Elsharafi M (2019) Improving oil recovery from shale oil reservoirs using cyclic cold carbon dioxide injection - an experimental study. Fuel. https ://doi.org/10.1016/j.fuel.2019.05.169

Erdogan F, Sih GC (1963) On the crack extension in plates under plane loading and transverse shear. J Basic Eng. https://doi. org/10.1115/1.3656897

Fakoya MF, Shah SN (2016) Relative viscosity of hydraulic fracturing fluids containing nanoparticles. Soc Pet Eng. https://doi. org/10.2118/180458-MS

Fatahi H, Hossain MM, Sarmadivaleh M (2017) Numerical and experimental investigation of the interaction of natural and propagated hydraulic fracture. J Nat Gas Sci Eng 37:409-424. https://doi. org/10.1016/j.jngse.2016.11.054

Feng Y, Gray KE (2017) Review of fundamental studies on lost circulation and wellbore strengthening. J Pet Sci Eng 152:511-522. https://doi.org/10.1016/j.petrol.2017.01.052

Feng Y, Gray KE (2018) Effects of porous properties of rock on nearwellbore hydraulic fracture complexity. In: Unconventional resources technology conference. https://doi.org/10.15530/ URTEC-2018-2883153

French S, Gil I, Cawiezel K, Yuan C, Gomaa A, Schoderbek D (2019) Hydraulic fracture modeling and innovative fracturing treatment design to optimize perforation cluster efficiency, lateral placement, and production results in a mancos shale gas appraisal well. In: Unconventional resources technology conference. https ://doi.org/10.15530/urtec-2019-464

Fu P, Cruz L, Moos D, Settgast RR, Ryerson FJ (2015) Numerical investigation of a hydraulic fracture bypassing a natural fracture in 3D. American Rock Mechanics Association, ARMA-2015-671

Fu W, Ames BC, Bunger AP, Savitski AA (2015) An experimental study on interaction between hydraulic fractures and partiallycemented natural fractures. American Rock Mechanics Association, ARMA-2015-132

Gale JFW, Elliott SJ, Laubach SE (2018) Hydraulic fractures in core from stimulated reservoirs: core fracture description of HFTS Slant Core, Midland Basin, West Texas. In: Unconventional resources technology conference. https://doi.org/10.15530/ URTEC-2018-2902624

Geertsma J, de Klerk F (1969) A rapid method of predicting width and extent of hydraulically induced fractures. J Pet Technol 21:15711581. https://doi.org/10.2118/2458-PA

Germanovich LN, Hurt RS, Ayoub JA, Siebrits E, Norman D, Ispas I, Montgomery CT (2012) Experimental study of hydraulic fracturing in unconsolidated materials. Soc Pet Eng. https://doi. org/10.2118/151827-MS

Ghaderi A, Taheri-Shakib J, Sharif Nik MA (2018a) The distinct element method (DEM) and the extended finite element method (XFEM) application for analysis of interaction between hydraulic and natural fractues. J Pet Sci Eng 171:422-430. https://doi. org/10.1016/j.petrol.2018.06.083

Ghaderi A, Taheri-Shakib J, Sharif Nik MA (2018b) The effect of natural fracture on the fluid leak-off in hydraulic fracturing treatment. Petroleum. https://doi.org/10.1016/j.petlm.2018.05.006

Gil I, Nagel N, Sanchez-Nagel M, Damjanac B (2011) The effect of operational parameters on hydraulic fracture propagation in naturally fractured reservoirs-getting control of the fracture optimization process. American Rock Mechanics Association, ARMA-11-391

Green S, Walsh J, McLennan J, Forbes B (2017) Hydraulic fracture propagation in steps considering different fracture fluids. American Rock Mechanics Association, ARMA-2017-0555

Grieser WV, Bray JM (2007) Identification of production potential in unconventional reservoirs. Soc Pet Eng. https://doi. org/10.2118/106623-MS

$\mathrm{Gu} \mathrm{H}$, Weng X (2010) Criterion for fractures crossing frictional interfaces at non-orthogonal angles. American Rock Mechanics Association, ARMA-10-198

Gu H, Weng X, Lund JB, Mack MG, Ganguly U, Suarez-Rivera R (2011) Hydraulic fracture crossing natural fracture at nonorthogonal angles, a criterion, its validation and applications. Soc Pet Eng. https://doi.org/10.2118/139984-MS

Guo J, Zhao X, Zhu H, Zhang X, Pan R (2015) Numerical simulation of interaction of hydraulic fracture and natural fracture based on the cohesive zone finite element method. J Nat Gas Sci Eng 25:180-188. https://doi.org/10.1016/j.jngse.2015.05.008

Guo J, Luo B, Lu C, Lai J, Ren J (2017) Numerical investigation of hydraulic fracture propagation in a layered reservoir using the cohesive zone method. Eng Fract Mech 186:195-207. https:// doi.org/10.1016/j.engfracmech.2017.10.013

Han Y, Damjanac B, Nagel N (2012) A microscopic numerical system for modeling interaction between natural fractures and hydraulic fracturing. American Rock Mechanics Association

He Q, Suorineni F, Oh J (2015) Modeling interaction between natural fractures and hydraulic fractures in block cave mining. American Rock Mechanics Association, ARMA-2015-842

Hou B, Chen M, Jin Y, Lin B, Diao C, Zhang X (2015) Optimum condition of hydraulic fracture-natural fracture interaction in shale block experiments. American Rock Mechanics Association, ARMA-2015-089

Hu D, Matzar L, Martysevich VN (2014) Effect of natural fractures on eagle ford shale mechanical properties. Soc Pet Eng. https://doi. org/10.2118/170651-MS

Huang J, Safari R, Mutlu U, Burns K, Geldmacher I, McClure M, Jackson S (2014) Natural-hydraulic fracture interaction: microseismic observations and geomechanical predictions. In: Unconventional resources technology conference. https://doi.org/10.15530 /URTEC-2014-1921503

Huang J, Morris JP, Fu P, Settgast RR, Sherman CS, Ryerson FJ (2018) Hydraulic fracture height growth under the combined influence of stress barriers and natural fractures. Soc Pet Eng. https://doi. org/10.2118/189861-MS

Ispas I, Eve R, Hickman RJ, Keck RG, Willson SM, Olson KE (2012) Laboratory testing and numerical modelling of fracture propagation from deviated wells in poorly consolidated formations. Soc Pet Eng. https://doi.org/10.2118/159262-MS

Jeffrey RG (1989) The combined effect of fluid lag and fracture toughness on hydraulic fracture propagation. Soc Pet Eng. https://doi. org/10.2118/18957-MS

Johnson S, Arson C, Settgast R (2013) Multi-scale fracture creation and network generation during hydraulic fracturing. American Rock Mechanics Association, ARMA-2013-584 
Kamali A, Ghassemi A (2019) DFIT considering complex interactions of hydraulic and natural fractures. Soc Pet Eng. https://doi. org/10.2118/194348-MS

Katz O, Reches ZE (2004) Microfracturing, damage, and failure of brittle granites. J Geophys Res Solid Earth. https://doi. org/10.1029/2002JB001961

Kear J, Kasperczyk D, Zhang X, Jeffrey RG, Chuprakov D, Prioul $R$ (2017) 2D experimental and numerical results for hydraulic fractures interacting with orthogonal and inclined discontinuities. American Rock Mechanics Association

Keshavarzi R, Jahanbakhshi R (2013) Investigation of hydraulic and natural fracture interaction: numerical modeling or artificial intelligence? In: International society for rock mechanics and rock engineering

Keshavarzi R, Mohammadi S, Bayesteh H (2012) Hydraulic fracture propagation in unconventional reservoirs: the role of natural fractures. American Rock Mechanics Association, ARMA-2012-129

Khristianovich SA, Zheltov VP (1955) Formation of vertical fractures by means of highly viscous fluid. In: World petroleum congress, pp 579-586

King GE (2012) Hydraulic fracturing 101: what every representative, environmentalist, regulator, reporter, investor, university researcher, neighbor and engineer should know about estimating frac risk and improving frac performance in unconventional gas and oil wells. Soc Pet Eng. https://doi.org/10.2118/15259 6-MS

King GE (2014) 60 Years of multi-fractured vertical, deviated and horizontal wells: What have we learned? Soc Pet Eng. https:// doi.org/10.2118/170952-MS

Kolawole O, Ispas I (2019a) How hydraulic fractures interact with natural fractures: a review and new observations. American Rock Mechanics Association, ARMA-2019-0018

Kolawole O, Ispas I (2019b) Data for: interaction between hydraulic fractures and natural fractures: a review. Mendeley Data. https ://doi.org/10.17632/255hrzvkrf.4

Kolawole F, Atekwana EA, Ismail A (2017) Near-surface electrical resistivity investigation of coseismic liquefaction-induced ground deformation associated with the 2016 Mw5.8 Pawnee, Oklahoma, earthquake. Seismol Res Lett 88(4):1017-1023

Kolawole F, Atekwana EA, Laó-Dávila DA, Abdelsalam MG, Chindandali PR, Salima J, Kalindekafe L (2018a) Active deformation of Malawi rift's north basin Hinge zone modulated by reactivation of preexisting Precambrian Shear zone fabric. Tectonics 37(3):683-704

Kolawole O, Federer-Kovács G, Szabó I (2018b) Formation susceptibility to wellbore instability and sand production in the Pannonian Basin, Hungary. American Rock Mechanics Association, ARMA-2018-221

Kolawole F, Johnston C, Chang J, Marfurt KJ, Reches Z, Carpenter BM (2018c) Characterization of pre-existing structures in the basement of Oklahoma with implications for induced seismicity. Geol Soc Am. https://doi.org/10.1130/abs/2018AM-316528

Kolawole O, Esmaeilpour S, Hunky R, Saleh L, Ali-Alhaj HK, Marghani M (2019) Optimization of hydraulic fracturing design in unconventional formations: impact of treatment parameters. Soc Pet Eng. https://doi.org/10.2118/198031-MS

Kresse O, Weng X, Wu R, Gu H (2012) Numerical modeling of hydraulic fractures interaction in complex naturally fractured formations. American Rock Mechanics Association, ARMA-2012-292

Kumar D, Ghassemi A (2019a) Modeling and analysis of proppant transport and deposition in hydraulic/natural fracture networks. In: Unconventional resources technology conference. https://doi. org/10.15530/urtec-2019-243

Kumar D, Ghassemi A (2019b) Multistage hydraulic fracturing of EGS wells with application to FORGE. In: Proceedings of 44th workshop on geothermal reservoir engineering, Stanford University, Stanford, CA, USA, 11-13 February

Lecampion B, Jeffrey R, Detournay E (2004) Real-time estimation of fracture volume and hydraulic fracturing treatment efficiency. American Rock Mechanics Association, ARMA-04-519

Lee HP, Olson JE, Holder J, Gale JFW, Myers RD (2015) The interaction of propagating opening mode fractures with preexisting discontinuities in shale. J Geophys Res Solid Earth 120:169-181. https://doi.org/10.1002/2014JB011358

Lee HP, Razavi O, Olson JE (2018) Hydraulic fracture interaction with cemented natural fracture: a three dimensional discrete element method analysis. Soc Pet Eng. https://doi.org/10.2118/18985 2-MS

Li W, Yang C (2018) Discrete element modeling of thermal cracking of rock salt with interbedded layers. In: International society for rock mechanics and rock engineering, ISRM-ARMS10-2018-041

Mack MG (2016) The effects of stress changes and natural fractures on hydraulic fracture interactions. American Rock Mechanics Association, ARMA-2016-284

Maity D, Ciezobka J (2018) Correlating microseismicity with relevant geophysical and petrophysical data to understand fracturing process during hydraulic stimulation: a case study from the Permian Basin. Society of Exploration Geophysicists, SEG-2018-2995006

Maity D, Ciezobka J (2019a) An interpretation of proppant transport within the stimulated rock volume at the hydraulic-fracturing test site in the Permian basin. Soc Pet Eng. https://doi. org/10.2118/194496-PA

Maity D, Ciezobka J (2019b) Designing a robust proppant detection and classification workflow using machine learning for subsurface fractured rock samples post hydraulic fracturing operations. J Pet Sci Eng 172:588-606. https://doi.org/10.1016/j.petro 1.2018.09.062

Maity D, Ciezobka J, Eisenlord S (2018) Assessment of in situ Proppant placement in SRV using through- fracture core sampling at HFTS. In: Unconventional resources technology conference. https://doi.org/10.15530/URTEC-2018-2902364

Maxwell SC, Waltman C, Warpinski NR, Mayerhofer MJ, Boroumand N (2009) Imaging seismic deformation induced by hydraulic fracture complexity. SPE Reserv Eval Eng 12(01):45-48. https ://doi.org/10.2118/102801-PA

McClure MW, Horne RN (2013) Discrete fracture network modeling of hydraulic stimulation: coupling flow and geomechanics. SpringerBriefs in Earth Sciences, 978-3-319-00383-2. https:// doi.org/10.1007/978-3-319-00383-2

McLennan JD, Picardy JC (1985) Pseudo-three-dimensional fracture growth modeling. American Rock Mechanics Association. ARMA-85-0323-1

McLennan J, Potocki D (2013) Hydraulic fracturing complexity: interaction between hydraulic and natural fractures. American Association of Petroleum Geologists

Medlin WL, Fitch JL (1988) Abnormal treating pressures in massive hydraulic fracturing treatments. Soc Pet Eng. https://doi. org/10.2118/12108-PA

Meng C, de Pater CJ (2010) Hydraulic fracture propagation in prefractured natural rocks. American Rock Mechanics Association, ARMA-10-318

Mighani S, Lockner DA, Kilgore BD, Sheibani F, Evans B (2018a) Interaction between hydraulic fracture and a preexisting fracture under triaxial stress conditions. Soc Pet Eng. https://doi. org/10.2118/189901-MS

Mighani S, Lockner DA, Kilgore BD, Evans B (2018b) Role of Fault Gouge during interaction between hydraulic fracture and a preexisting fracture. American Rock Mechanics Association, ARMA-18-0901

Mikaeili E, Schrefler B (2018) XFEM, strong discontinuities and second-order work in shear band modeling of saturated porous

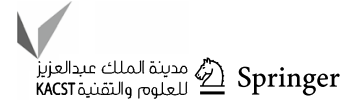


media. Acta Geotechnil 13:1249. https://doi.org/10.1007/s1144 0-018-0734-6

Milad B, Slatt R (2018) Impact of lithofacies variations and structural changes on natural fracture distributions. Interpretation 6(4):T873-T887. https://doi.org/10.1190/INT-2017-0138.1

Milad B, Ghosh S, Suliman M, Slatt RM (2018) Upscaled DFN models to understand the effects of natural fracture properties on fluid flow in the Hunton Group tight Limestone. In: Unconventional resources technology conference. https://doi.org/10.15530 /URTEC-2018-2903038

Milanese E, Cao TD, Simoni L, Schrefler BA (2018) Fracturing in dry and saturated Porous Media. In: Oñate E, Peric D, deSouzaNeto E, Chiumenti M (eds) Advances in computational plasticity. Computational methods in applied sciences, vol 46. Springer, Cham, pp 265-288. https://doi.org/10.1007/978-3319-60885-3_13

Moradi A, Tokhmechi B, Rasouli V, Marji MF (2017) A comprehensive numerical study of hydraulic fracturing process and its affecting parameters. Geotechnol Geol Eng 35:1035-1050. https://doi.org/10.1007/s10706-017-0159-2

Moradian Z, Fathi A, Evans B (2016) Shear reactivation of natural fractures in hydraulic fracturing. American Rock Mechanics Association, ARMA-2016-829

Moronkeji D, Cazeneuve E, Franquet J, Sandia MR, Velo D (2015) Borehole breakout modeling and stress profiling using anisotropic mechanical properties: case study in a tight basement and overlying formation. Soc Pet Eng. https://doi. org/10.2118/175607-MS

Morris JP, Fu P, Settgast RR, Sherman CS, Friedrich M, Leonard $P$ (2016) The combined influence of stress barriers and natural fractures upon hydraulic fracture height growth. American Rock Mechanics Association, ARMA-2016-886

Nagel NB, Sanchez-Nagel MA, Garcia X, Lee B (2012) A numerical evaluation of the geomechanical interactions between a hydraulic fracture stimulation and a natural fracture system. American Rock Mechanics Association

Napier JAL, Peirce AP (2014) Interaction of multiple fluid-driven fractures with pre-existing discontinuities. American Rock Mechanics Association, ARMA-2014-7071

Nikam A, Awoleke OO, Ahmadi M (2016) Modeling the interaction between natural and hydraulic fractures using three dimensional finite element analysis. Soc Pet Eng. https://doi. org/10.2118/180364-MS

Nordgren R (1972) Propagation of vertical hydraulic fractures. J Pet Technol 253((SPE-3009-PA)):306-314. https://doi. org/10.2118/3009-PA

Olson JE, Bahorich B, Holder J (2012) Examining hydraulic fracture: natural fracture interaction in hydrostone block experiments. Soc Pet Eng. https://doi.org/10.2118/152618-MS

Ouenes A, Bachir A, Paryani M, Smaoui R (2015) Estimation of propped volume permeability using strain from geomechanical modeling of interacting hydraulic and natural fractures-application to the eagle ford. Soc Pet Eng. https://doi. org/10.2118/175971-MS

Oyedokun O, Schubert J (2017) An energy based analytical method to predict the influence of natural fractures on hydraulic fracture propagation. J Nat Gas Sci Eng 44:351-364. https://doi. org/10.1016/j.engfracmech.2017.11.020

Pankaj P, Li J (2018) Impact of natural fractures beyond the hydraulic fracture complexity in unconventional reservoirs-a permian case study. In: Unconventional resources technology conference. https://doi.org/10.15530/URTEC-2018-2874839

Parsegov SG, Nandlal K, Schechter DS, Weijermars R (2018) Physics-driven optimization of drained rock volume for multistage fracturing: field example from the Wolfcamp formation,
Midland Basin. In: Unconventional resources technology conference. https://doi.org/10.15530/URTEC-2018-2879159

Paryani M, Poludasu S, Sia D, Bachir A, Ouenes A (2016) Estimation of optimal frac design parameters for asymmetric hydraulic fractures as a result of interacting hydraulic and natural fractures-application to the eagle ford. Soc Pet Eng. https:// doi.org/10.2118/180460-MS

Perkins T, Kern L (1961) Widths of hydraulic fractures. J Pet Technol. https://doi.org/10.2118/89-PA

Pettitt WS, Hazzard J, Riahi A, Maxwell S, Blankenship D (2018) Simulated microseismicity in geomechanical models with natural and induced fractures. SEG Tech Progr Expand Abstr. https ://doi.org/10.1190/segam2018-2998157.1

Potluri NK, Zhu D, Hill AD (2005) The effect of natural fractures on hydraulic fracture propagation. Soc Pet Eng. https://doi. org/10.2118/94568-MS

Potocki DJ (2012) understanding induced fracture complexity in different geological settings using DFIT net fracture pressure. Soc Pet Eng. https://doi.org/10.2118/162814-MS

Renshaw CE, Pollard DD (1995) An experimentally verified criterion for propagation across unbounded frictional interfaces in brittle, linear elastic materials. Int J Rock Mech Min Sci Geomech Abstr 32(3):237-249. https://doi.org/10.1016/01489062(94)00037-4

Riahi A, Damjanac B (2013) Numerical study of the interaction between injection and the discrete fracture network in enhanced geothermal reservoirs. American Rock Mechanics Association, ARMA-2013-333

Rutledge JT, Phillips WS (2003) Hydraulic stimulation of natural fractures as revealed by induced microearthquakes, Carthage Cotton Valley gas field, east Texas. Geophysics 68(2):441-452. https://doi.org/10.1190/1.1567214

Sarvaramini E, Garagash DI (2016) Poroelastic effects in reactivation of a fingerlike hydraulic fracture. ASME J Appl Mech 83(6):061011-061018. https://doi.org/10.1115/1.4032908

Schwartz B, Huffman K, Thornton D, Elsworth D (2019) A strain based approach to calculate disparities in pore structure between shale basins during permeability evolution. J Nat Gas Sci Eng. https://doi.org/10.1016/j.jngse.2019.05.006

Sebastian H, Gil I, Graff M, Wampler J, Merletti G, Sun T, Cadwallader S, Patel H, Spain D, Cawiezel K, Smith P, Keck R (2015) 3-D hydraulic fracturing and reservoir flow modeling-key to the successful implementation of a geo-engineered completion optimization program in the Eagle Ford Shale. In: Unconventional resources technology conference. https://doi. org/10.15530/URTEC-2015-2149711

Segall P, Pollard DD (1983) Nucleation and growth of strike slip faults in granite. J Geophys Res Solid Earth 88(B1):555-568. https://doi.org/10.1029/JB088iB01p00555

Seok Yoon J, Zang A, Stephansson O, Hofmann H, Zimmermann G (2017) Discrete element modelling of hydraulic fracture propagation and dynamic interaction with natural fractures in hard rock. In: International Society for rock mechanics and rock engineering

Serebrinsky SA, Winograd EA, Celleri HM, Sánchez M, Alvarez JP, Hryb DE, López RG (2017) Finite elements simulation of the interaction of a hydraulic fracture with a natural fracture. American Rock Mechanics Association, ARMA-2017-1044

Sesetty V, Ghassemi A (2012) Simulation of hydraulic fractures and their interactions with natural fractures. American Rock Mechanics Association, ARMA-2012-331

Shrivastava K, Agrawal S, Kumar A, Sharma MM (2018) 3-D interactions of hydraulic fractures with natural fractures. Soc Pet Eng. https://doi.org/10.2118/191447-18IHFT-MS 
Soliman MY, Wigwe M, Alzahabi A, Pirayesh E, Stegent N (2014) Analysis of fracturing pressure data in heterogeneous shale formations. Hydraul Fract J 1(2):8-12

Song W, Jinzhou Z, Yongming L (2014) Hydraulic fracturing simulation of complex fractures growth in naturally fractured shale gas reservoir. Arab J Sci Eng 39:7411. https://doi.org/10.1007/s1336 9-014-1221-5

Suboyin A, Rahman MM, Haroun M, Shaik AR (2018) A novel dynamic assessment of multi-stage hydraulic fracture propagation in presence of natural fractures in shale gas reservoirs. Soc Pet Eng. https://doi.org/10.2118/192811-MS

Sun X, Zhang S, Ma X, Zou Y, Lin G (2019) Experimental investigation on propagation behavior of hydraulic fractures in coal seam during refracturing. Geofluids 2019:4278543. https://doi. org $/ 10.1155 / 2019 / 4278543$

Taheri-Shakib J, Ghaderi A, Hashemi A (2016a) Analysis of interaction between hydraulic and natural fractures. Fract Mech Prop Patterns Behav Technol. https://doi.org/10.5772/64831

Taheri-Shakib J, Ghaderi A, Hosseini S, Hashemi A (2016b) Debonding and coalescence in the interaction between hydraulic and natural fracture: accounting for the effect of leak-off. J Nat Gas Sci Eng 36A:454-462. https://doi.org/10.1016/j. ngse.2016.10.056

Taheri-Shakib J, Ghaderi A, Sharif Nik MA (2018) Numerical study of influence of hydraulic fracturing on fluid flow in natural fractures. Petroleum. https://doi.org/10.1016/j.petlm.2018.10.005

Taleghani AD, Olson JE (2011) Numerical modeling of multistrandedhydraulic-fracture propagation: accounting for the interaction between induced and natural fractures. Soc Pet Eng. https://doi. org/10.2118/124884-PA

Taleghani AD, Olson JE (2013) How natural fractures could affect hydraulic-fracture geometry. Soc Pet Eng. https://doi. org/10.2118/167608-PA

Taleghani AD, Gonzalez M, Shojaei A (2016) Overview of numerical models for interactions between hydraulic fractures and natural fractures: challenges and limitations. Comput Geotechnol 7:361368. https://doi.org/10.1016/j.compgeo.2015.09.009

Taleghani AD, Gonzalez-Chavez M, Yu H, Asala H (2018) Numerical simulation of hydraulic fracture propagation in naturally fractured formations using the cohesive zone model. J Pet Sci Eng 165:42-57. https://doi.org/10.1016/j.petrol.2018.01.063

Tang J, Wu K, Li Y, Hu X, Liu Q, Ehlig-Economides C (2018) Numerical investigation of the interactions between hydraulic fracture and bedding planes with non-orthogonal approach angle. Eng Fract Mech 200:1-16. https://doi.org/10.1016/j.engfracmec h.2018.07.010

Tarokh A, Blanksma DJ, Fakhimi A, Labuz JF (2016) Fracture initiation in cavity expansion of rock. Int J Rock Mech Min Sci 85:84-91. https://doi.org/10.1016/j.ijrmms.2016.03.008

Toth AN, Szucs P, Pap J, Nyikos A, Fenerty DK (2018) Converting abandoned Hungarian oil and gas wells into geothermal sources. In: Proceedings of 43rd workshop on geothermal reservoir engineering, Stanford University, Stanford, CA, USA, 12-14 February

Toth AN, Nyikos A, Fenerty DK (2019) Prospects for geothermal power projects in Hungary. In: Proceedings of European geothermal congress, Den Haag, The Netherlands, 11-14 June

Umholtz N, Ouenes A (2015) Optimal fracing near faults-quantifying the interaction between natural and hydraulic fractures using geomechanical modeling. Soc Pet Eng. https://doi. org/10.2118/176932-MS

Walton I, McLennan J (2013) The role of natural fractures in shale gas production. In: International Society for rock mechanics and rock engineering, ISRM-ICHF-2013-046

Wan X, Rasouli V, Damjanac B, Torres M, Qiu D (2019) Numerical simulation of integrated hydraulic fracturing, production and refracturing treatments in the Bakken formation. American Rock Mechanics Association

Wang H (2019) Hydraulic fracture propagation in naturally fractured reservoirs: complex fracture or fracture networks. J Nat Gas Sci Eng 68:102911. https://doi.org/10.1016/j.jngse.2019.102911

Wang W, Olson JE, \& Prodanovic M (2013) Natural and hydraulic fracture interaction study based on semi-circular bending experiments. In: Unconventional resources technology conference. https://doi.org/10.15530/URTEC-1576910-MS

Wang Y, Li CH, Hu YZ, Mao TQ (2017) Laboratory investigation of hydraulic fracture propagation using real-time ultrasonic measurement in shale formations with random natural fractures. Environ Earth Sci 76:768. https://doi.org/10.1007/s12665-017-7038-2

Wang W, Olson JE, Prodanovic M, Schultz RA (2018a) The impact of natural fracture thickness on hydraulic fracture interaction mechanics. In: Unconventional resources technology conference. https://doi.org/10.15530/URTEC-2018-2902343

Wang W, Olson JE, Prodanovic M, Schultz RA (2018b) Interaction between cemented natural fractures and hydraulic fractures assessed by experiments and numerical simulations. J Pet Sci Eng 167:506-516. https://doi.org/10.1016/j.petrol.2018.03.095

Wang X, Shi F, Liu C, Lu D, Liu H, Wu H (2018c) Extended finite element simulation of fracture network propagation in formation containing frictional and cemented natural fractures. J Nat Gas Sci Eng 50:309-324. https://doi.org/10.1016/j.jngse.2017.12.013

Warpinski NR (1991) Hydraulic fracturing in tight, Fissured Media. JPT Soc Pet Eng 1:1. https://doi.org/10.2118/20154-PA

Warpinski NR, Teufel LW (1987) Influence of geologic discontinuities on hydraulic fracture propagation (includes associated papers 17011 and 17074). JPT. https://doi.org/10.2118/13224-PA

Warpinski NR, Lorenz JC, Branagan PT, Myal FR, Gall BL (1993) Examination of a cored hydraulic fracture in a deep gas well (includes associated papers 26302 and 26946). SPEPF Soc Pet Eng. https://doi.org/10.2118/22876-PA

Wheeler MF, Srinivasan S, Lee S, Singh M (2019) Unconventional reservoir management modeling coupling diffusive zone/phase field fracture modeling and fracture probability maps. Soc Pet Eng. https://doi.org/10.2118/193830-MS

Wigwe ME, Soliman MY, Pirayesh E (2018) Actual hydraulic fracture length determination using a new technique for shale fracturing data analysis in real time. American Rock Mechanics Association, ARMA-2018-437

Wigwe M, Kolawole O, Watson M, Ispas I, Li W (2019a) Influence of fracture treatment parameters on hydraulic fracturing optimization in unconventional formations. In: Proceedings of ARMACUPB geothermal international conference, Beijing, China, 5-8 August. ARMA-CUPB-19-3666

Wigwe ME, Watson MC, Giussani A, Nasir E, Dambani S (2019b) Application of geographically weighted regression to model the effect of completion parameters on oil production-case study on unconventional wells. Soc Pet Eng. https://doi. org/10.2118/198847-MS

William B, Daniel V, Radonjic M (2019) Nature's solution to wellbore gas-leakage: gilsonite. American Rock Mechanics Association. ARMA-2019-1544

Williams-Stroud SC, Barker WB, Smith KL (2012a) Induced hydraulic fractures or reactivated natural fractures? Modeling the response of natural fracture networks to stimulation treatments. American Rock Mechanics Association, ARMA-2012-667

Williams-Stroud SC, Barker WB, Smith KL (2012b) Induced hydraulic fractures or reactivated natural fractures? Modeling the response of natural fracture networks to stimulation treatments. American Rock Mechanics Association. ARMA-2012-667

Williams-Stroud SC, Barker WB, Smith KL (2012c) Modelling the response of natural fracture networks to induced hydraulic fractures in stimulation treatments. First Break 30(7):71-75

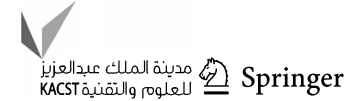


Willson S, Armagost K (2004) Spotlight on R\&D: drilling and completions-striving for the par-5 "hole in one". Soc Pet Eng. https:// doi.org/10.2118/0504-0034-JPT

Wu K, Olson JE (2014) Mechanics analysis of interaction between hydraulic and natural fractures in shale reservoirs. In: Unconventional resources technology conference. https://doi.org/10.15530 /URTEC-2014-1922946

Wu R, Kresse O, Weng X, Cohen C-E, Gu H (2012) Modeling of interaction of hydraulic fractures in complex fracture networks. Soc Pet Eng. https://doi.org/10.2118/152052-MS

Xiao C, Tian L, Zhang Y, Hou T, Yang Y, Deng Y, Wang Y, Chen S (2017) A novel approach to detect interacting behavior between hydraulic fracture and natural fracture by use of semianalytical pressure-transient model. Soc Pet Eng. https://doi. org/10.2118/187954-PA

Xie J, Huang H, Ma H, Zeng B, Tang J, Yu W, Wu K (2018) Numerical investigation of effect of natural fractures on hydraulic-fracture propagation in unconventional reservoirs. J Nat Gas Sci Eng 54:143-153. https://doi.org/10.1016/j.jngse.2018.04.006

Xu W, Zhao J, Li Y, Rahman SS, Fu D, Chen X (2018) Numerical study of a hydraulic fracture interacting with a natural fracture under different geological and engineering parameters. Soc Pet Eng. https://doi.org/10.2118/192599-MS

Yan C, Zheng H (2017) FDEM-flow3D: a 3D hydro-mechanical coupled model considering the pore seepage of rock matrix for simulating three-dimensional hydraulic fracturing. Comput Geotech 81:212-228. https://doi.org/10.1016/j.compgeo.2016.08.014

Yang Y (2008) Using the formation breakdown pressure measured in prefrac test to predict natural fracture swarms in low-permeability carbonate at the Wattenberg field in the Denver Julesburg Basin. Soc Pet Eng. https://doi.org/10.2118/115207-MS

Yang X, Burghardt J, Zhang H, Zhang Y, Zhang F, Pei J, Qi C, Qui K, Whitney N (2016) Experimental study of hydraulic fracture/ natural fracture interaction on a tight sandstone formation. In: Unconventional resources technology conference. https://doi. org/10.15530/URTEC-2016-2460449

Yao Y, Wenhua W, Leon MK (2018) An energy based analytical method to predict the influence of natural fractures on hydraulic fracture propagation. Eng Fract Mech 189:232-245. https://doi. org/10.1016/j.engfracmech.2017.11.020

Yildirim B, Cao W, Shi J-Q, Durucan S, Korre A (2018a) Discrete element modelling of hydraulic fracture interaction with natural fractures in shale formations. American Rock Mechanics Association

Yildirim B, Cao W, Durucan S, Korre A, Wolf KH, Bakker R, Barnhoorn A (2018b) The effect of natural fracture heterogeneity on hydraulic fracture performance and seismic response in shale and coal formations. American Rock Mechanics Association ARMA-18-227

Zangeneh N, Eberhardt E, Bustin RM (2015) Investigation of the influence of natural fractures and in situ stress on hydraulic fracture propagation using a distinct-element approach. Can Geotech J 52:926-946. https://doi.org/10.1139/cgj-2013-0366

Zhang F, Qiu K, Yang X, Hao J, Yuan X, Burghardt J, Liu H, Dong J, Luo F (2015) A Study of the interaction mechanism between hydraulic fractures and natural fractures in the ks tight gas reservoir. Soc Pet Eng. https://doi.org/10.2118/174384-MS

Zhang Q, Zhang X-P, Ji P-Q (2018) Numerical study of interaction between a hydraulic fracture and a weak plane using the bondedparticle model based on moment tensors. Comput Geotech 105:79-93. https://doi.org/10.1016/j.compgeo.2018.09.012

Zhao Z, Zhang H, Guo J, Xiao Y, Zhao X (2016) Propagation criterion of hydraulic fractures at tip of natural fractures in shale reservoir. Electron J Geotech Eng 21(22):7073-7088

Zhao X, Wang T, Elsworth D, He Y, Zhou W, Zhuang L, Zeng J, Wang S (2018) Controls of natural fractures on the texture of hydraulic fractures in rock. J Pet Sci Eng 165:616-626. https:// doi.org/10.1016/j.petrol.2018.02.047

Zhao G-F, Yin Q, Russell AR, Li Y, Wu W, Li Q (2019a) On the linear elastic responses of the $2 \mathrm{D}$ bonded discrete element model. Int J Numer Anal Methods Geomech 43(1):166-182. https://doi. org/10.1002/nag.2858

Zhao Y, Zhang YF, He PF (2019b) A composite criterion to predict subsequent intersection behavior between a hydraulic fracture and a natural fracture. Eng Fract Mech 209:61-78. https://doi. org/10.1016/j.engfracmech.2019.01.015

Zhou J, Xue C (2011) Experimental investigation of fracture interaction between natural fractures and hydraulic fracture in naturally fractured reservoirs. Soc Pet Eng. https://doi.org/10.2118/14289 0 -MS

Zhou J, Huang H, Deo M (2015) Modeling the interaction between hydraulic and natural fractures using dual-lattice discrete element method. American Rock Mechanics Association, ARMA-2015-507

Zhou J, Huang H, Deo M (2016) Simulation of hydraulic and natural fracture interaction using a coupled DFN-DEM model. American Rock Mechanics Association, ARMA-2016-739

Zhu G, Sousa R, Abdulla MB, Abu Al-Rub R, Sassi M (2018) Numerical investigation of the interaction between hydraulic fractures and nature fractures at reservoir scale. American Rock Mechanics Association, ARMA-DFNE-18-0774

Zoback MD, Kohli A, Das I, Mcclure MW (2012) The importance of slow slip on faults during hydraulic fracturing stimulation of shale gas reservoirs. Soc Pet Eng. https://doi.org/10.2118/15547 6-MS

Publisher's Note Springer Nature remains neutral with regard to jurisdictional claims in published maps and institutional affiliations. 